\begin{tabular}{|c|l|}
\hline Title & $\begin{array}{l}\text { Energy dissipative photoprotective mechanism of carotenoid spheroidene from the photoreaction center of purple } \\
\text { bacteria Rhodobacter sphaeroides }\end{array}$ \\
\hline Author(s) & A rulmozhiraja, Sundaram; Nakatani, Naoki; Nakay ama, A kira; Hasegawa, Jun-ya \\
\hline Citation & $\begin{array}{l}\text { Physical chemistry chemical physics, 17(36), 23468-23480 } \\
\text { https://doi.org/10.1039/c5cp03089g }\end{array}$ \\
\hline Issue Date & 2015-08-04 \\
\hline Doc URL & http://hdl.handle.net/2115/62615 \\
\hline Type & article (author version) \\
\hline File Information & MS_150724b.pdf \\
\hline
\end{tabular}

Instructions for use 


\title{
Energy dissipative photo-protective mechanism of carotenoid spheroidene from the photoreaction center of purple bacteria Rhodobacter sphaeroides
}

\author{
Sundaram Arulmozhiraja ${ }^{[a]}$ Naoki Nakatani, ${ }^{[a]}$ Akira Nakayama, ${ }^{[a]}$ and Jun-ya \\ Hasegawa*[a, b] \\ [a] Catalysis Research Center, Hokkaido University, Kita 21, Nishi 10, Kita-ku, Sapporo \\ 001-0021, Japan \\ [b] JST-CREST \\ *hasegawa@cat.hokudai.ac.jp
}

\begin{abstract}
Carotenoid spheroidene (SPO) works for photoprotection in the photosynthetic reaction centers $(\mathrm{RC})$ and effectively dissipates its triplet excitation energy. Sensitized cis-totrans isomerization was proposed as the possible mechanism for a singlet-triplet energy crossing for the $15,15^{\prime}$-cis-SPO; however, it has been questioned recently. To understand the dissipative proto-protective mechanism of this important SPO and to overcome the existing controversies on this issue, we carried out a theoretical investigation using density functional theory on the possible triplet energy relaxation mechanism through the cis-to-trans isomerization. Together with the earlier experimental observations, the possible mechanism was discussed for the triplet energy relaxation of the 15,15'-cis-SPO. The result shows that complete cis-to-trans isomerization is not necessary. Twisting $\mathrm{C} 15-\mathrm{C} 15^{\prime}$ bond leads singlettriplet energy crossing at $\phi\left(14,15,15^{\prime}, 14^{\prime}\right)=77^{\circ}$ at the energy $32.5 \mathrm{~kJ} / \mathrm{mol}(7.7 \mathrm{kcal} / \mathrm{mol})$ higher than that of the $T_{1} 15,15^{\prime}$-cis minimum. Further exploration of the minimum-energy intersystem crossing (MEISC) point shows that triplet relaxation could happen at a less distorted structure $\left(\phi=58.4^{\circ}\right)$ with the energy height of $6.3 \mathrm{kcal} / \mathrm{mol}$. Another important reaction coordinate to reach the MEISC point is the bond-length alternation. The model truncation effect, the solvent effect, and the spin-orbit coupling were also investigated. The singlet-triplet crossing was also investigated for the 13,14-cis stereoisomer and locked-13,14cis-SPO. We also discussed the origin of the natural selection of cis over trans isomer in the $\mathrm{RC}$.
\end{abstract}

\section{Introduction}


Carotenoids in photosynthetic systems plays a dual role: as a light-harvester (LH) in antenna complexes and as a photo-protector (PP) in bacterial photosynthetic reaction centers (RCs). ${ }^{1-11}$ See more details in Electronic Supplementary Information (ESI). As a PP, carotenoid quenches triplet bacteriochlorophyll (BChl) special pair (SP) to prevent sensitized generation of singlet oxygen $\left({ }^{1} \Delta_{\mathrm{g}}\right) \cdot \underline{12}, \underline{13}$

In the RC of Rhodobacter (Rb.) sphaeroides, (see structure shown in Figures $\mathrm{S} 1$ in ESI), carotenoid spheroidene (SPO) locates just next to BChl (see Figure 1) and plays the photoprotective quencher role - when excess of light energy is supplied to the RCs under reducing conditions, it gives rise to reverse electron transfer and charge recombination at the special pair of BChls to generate the triplet state, which can result in the sensitized formation of harmful singlet oxygen. ${ }^{2}, \underline{14}, \underline{15}$ The triplet state of donor (special pair) is, however, normally quenched by SPO through energy transfer that produces a triplet SPO. $\frac{16-23}{2}$ This might be one of the main reasons for why this SPO bounded in the RC is in van der Walls contact with the accessory $\mathrm{BChl}$ on the $\mathrm{M}$ side though it does not participate directly in the electron transfer process.

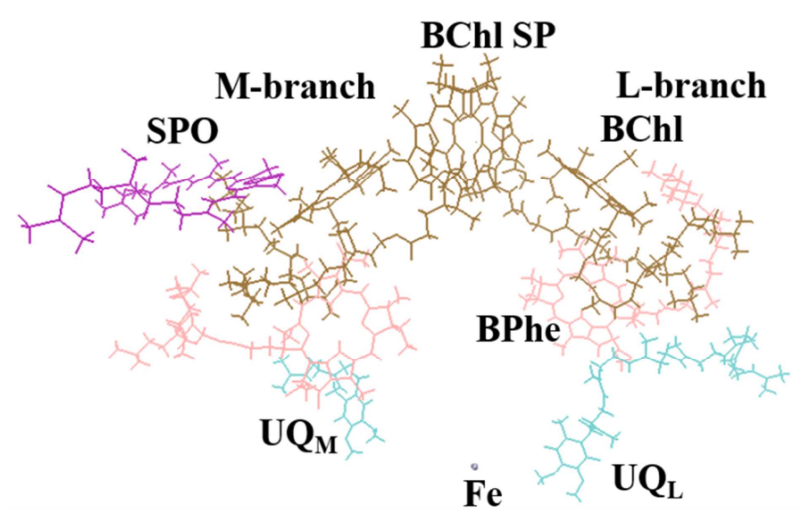

Figure 1. Reaction center of the purple bacteria Rhodobacter (Rb.) sphaeroides (PDB id 2J8C)..$^{24}$

Like other carotenoids, SPO is derived from the same basic structure of 8 isoprene units and has $10(n=10)$ conjugated $\mathrm{C}=\mathrm{C}$ double bonds. Interestingly, it has only been speculated that SPO selects its configuration depending on its major function: all-trans configuration in the antenna complexes and 15,15'-cis configuration (Figure 2) in the bacterial RCs, even though there are number of possible stereoisomers. 


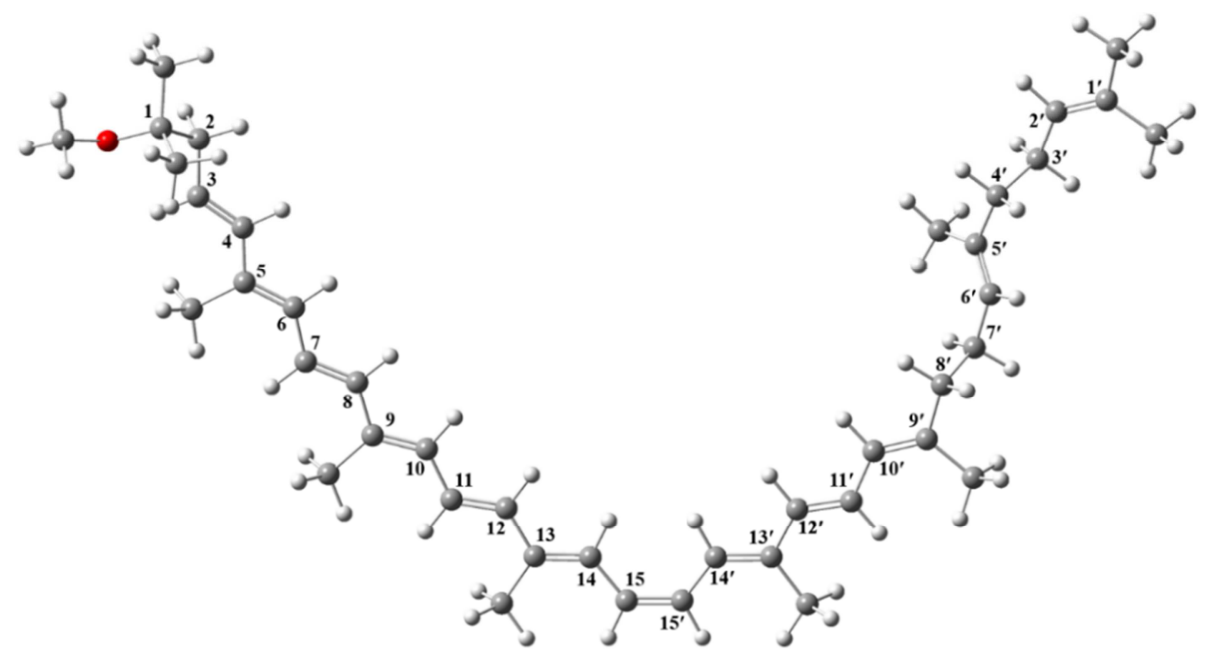

Figure 2. Structure (optimized) with important carbon atom numbering of 15,15'-cis-spheroidene.

Boucher and Gingras ${ }^{25}$ showed isomerization of the RC-bound 15-cis spirilloxanthin into all-trans based on electronic absorption spectroscopy in the case of Rhodospirillum rubrum S1. Kuki et al. $\frac{26}{}$ revealed the 15-cis to all-trans isomerization of the same carotenoid spirilloxanthin in the light and the reverse isomerization in the dark for a reduced form of RC from R. rubrum $\mathrm{S} 1$. By using transient Raman, transient absorption spectroscopies and by HPLC analysis of triplet-sensitized isomerization, Koyama and co-workers ${ }^{27-30}$ showed that $15,15^{\prime}$-cis isomer of SPO is extremely efficient in cis-to-trans isomerization in the $T_{1}$ state. From these studies, Koyama and co-workers postulated that the natural selection of the $15,15^{\prime}$-cis isomer of SPO in the RC enhances the ability of the carotenoid to dissipate triplet energy from SP via cis-to-trans isomerization in the protein. $\stackrel{26}{\underline{29}}$ This hypothesis has been supported by transient Raman spectroscopy of photoexcited triplet states of various cisisomers of $\beta$-carotene and SPO, which suggest more rapid dynamics for the isomerization of the $15,15^{\prime}$-cis carotenoid to its all-trans configuration compared to other cis-isomers of the molecules. It has been argued that cis-to-trans isomerization of 15,15'-cis carotenoid is a mechanism that enhances photoprotection. $\underline{25}, \underline{26}, \underline{29}, \underline{30}$

Later, Ohashi et al. $\frac{31}{}$ made a comparison of the ground state Raman spectrum of SPO in the reaction center of $R b$. sphaeroides 2.4.1 with that free in $n$-hexane solution and suggested that the RC-bound spheroidene takes a 15,15'-cis configuration, which is twisted around the central $\mathrm{C} 15-\mathrm{C} 15^{\prime}$ bond. The $T_{1}$ Raman spectrum indicated substantial twisting and in-plane distortion of the conjugated backbone. Based on these facts, a mechanism of triplet- 
energy dissipation by the RC-bound SPO, which involves an internal rotation around the central $\mathrm{C} 15-\mathrm{C} 15^{\prime}$ bond, is proposed. $\underline{31}$

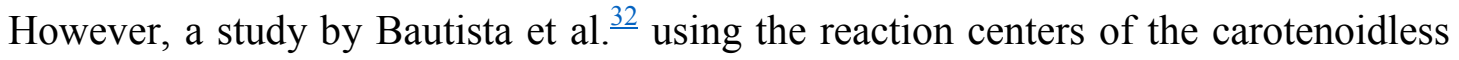
mutant $R b$. sphaeroides R-26.1 in which locked-15,15'-cis-spheroidene, which is incapable of undergoing cis-to-trans isomerization, was incorporated and revealed that there is no difference in either the spectroscopic properties or the photochemistry compared to $R b$. sphaeroides wild-type strain 2.4.1 RCs. The study concluded that the natural selection of the $15,15^{\prime}$-cis isomer of SPO for the incorporation into the RCs of $R b$. sphaeroides is determined by the nature of the carotenoid binding pocket in the pigment-protein complex. Nevertheless, later studies by Koyama and co-workers ${ }^{33}, \underline{34}$ supported their earlier assumption that the isomer geometry influences the manner in which the excited-state energy is dissipated (quenched) and cis-SPO conformer has an advantage over its trans counterpart in quenching the triplet energy. Their arguments are the following: (1) The quantum yield and the rate of cis-to-trans isomerization is maximum for the 15,15'-cis conformer in its triplet state and its rate of $T_{1} \rightarrow S_{0}$ intersystem crossing is 6 times larger than that of the trans $T_{1}$ species; (2) Among the selected cis isomers, 15,15'-cis has the highest rate of sensitized cis-to-trans isomerization; (3) The rate of isomerization is on the same order of magnitude as the rate of intersystem crossing for 15,15'-cis. They argued that these results clearly indicate the advantage for the cis conformer in the triplet-energy dissipation and the rotational motion around the $\mathrm{C} 15=\mathrm{C} 15^{\prime}$ bond initiates the $T_{1} \rightarrow S_{0}$ relaxation. Therefore, the usage of the $15,15^{\prime}$-cis configuration is expected to be most advantageous in dissipating the triplet energy. Koyama and co-workers $\stackrel{33}{3}, \underline{34}$ also updated their hypothetical mechanism of triplet-energy dissipation and concluded that this fast intersystem crossing should take place during the rotation before reaching the trans configuration or even within the $15,15^{\prime}$-cis $T_{1}$ potential minimum.

Yet, studies by Pendon et al. $\frac{35-37}{}$ in 2006 concluded against the hypothesis drawn by Koyama and co-workers. They reported ultrafast time-resolved spectroscopic studies of two pairs of stable geometric isomers of carotenoids including trans- SPO and 13,14-locked-cisSPO, the latter of which is incapable of undergoing cis-to-trans isomerization at C13-C14 bond. Their results reveal only a small difference in spectra, decay dynamics, and transfer times. With these results along with the fact that carotenoids occupy narrow binding pockets in semi-rigid environments in photosynthetic pigment-protein complexes, $\frac{38}{}$ which could 
prevent them to undergo configurational isomerization in site, they claim that there does not appear to be any built-in advantage in either triplet energy transfer or triplet decay afforded to cis- over trans-carotenoids owing simply to their distinct geometric isomeric forms. In parallel, in the same year, Koyama and co-workers ${ }^{39}$ examined the $T_{1}$ state of the RC-bound $15,15^{\prime}$-cis- SPO using the time-resolved electron paramagnetic resonance spectroscopy at low temperatures, and their results support their earlier hypothetical mechanism of triplet-energy dissipation through rotational motions around the central double bonds.

One more fact is that though it is broadly accepted that SPO in the $R b$. sphaeroides photosynthetic RC exists in the 15,15'-cis configuration, possibility of the existence of other conformer is not completely ruled out. Recent resonance Raman combined with density functional theory (DFT) studies ${ }^{40-42}$ concluded that wild-type RC of $R b$. sphaeroides contain only 15,15'-cis conformer of SPO while the reconstituted R26 RC contains SPO in both $15,15^{\prime}$-cis and 13,14-cis configurations. So it is important to study the triplet state and triplet energy dissipation mechanism of the 13,14-cis conformer too.

Foregoing facts disclose the need for a complete investigation on the triplet-energy dissipation mechanism of SPO in the RCs. Moreover, furthering the knowledge of triplet excited-state dynamics of this carotenoid can not only solve this divisive issue on whether natural selection of stereoisomers has physiological significance or not but it also can resolve a knot in the most important yet highly complicated photosynthetic RC science. Hence we decide to investigate the triplet-energy dissipative mechanism of spheroidene by using theoretical calculations. To the best of our knowledge, most of the earlier theoretical studies concerning spectroscopy, and quenching mechanism were made on singlet excited states. $\frac{43-53}{}$ Also, though adiabatic triplet excitation energy of carotenoid compounds is studied ${ }^{46,}, \underline{48}$, there is no report on the potential energy surfaces for the triplet-state quenching in carotenoid.

The main aim of the present study is to understand the quenching mechanism of the carotenoid SPO, i.e., the $T_{1} \rightarrow S_{0}$ relaxation mechanism. As detailed above, sensitized cis-totrans isomerization is a possible mechanism for SPO to dissipate its triplet energy and hence we gave particular importance in studying the potential energy surface along the rotation around the central C-C double bond. This paper is constituted as follows. In section 2, computational details were explained. In section 3, our results were summarized: the structures and energetics of the singlet and triplet states in cis and trans configurations in subsection 3.1, DFT results for the triplet-singlet crossing along the $\mathrm{C} 15-\mathrm{C} 15$ ' angles in 
subsection 3.2, CASSCF results in subsection 3.3, and the DFT results for the 13,14-cis SPO and the locked-13,14-cis SPO to rationalize experimental results in subsections 3.4 and 3.5, respectively. In section 4, we compared the present results with the previous experimental findings and discussed the relaxation mechanism. Finally, a brief conclusion was given in section 5. We note that our present study is based on the gas-phase calculations; however, the present results give meaningful conclusions over the existing controversies on this important subject.

\section{Computational details}

The initial structure of the $15,15^{\prime}$-cis-SPO was taken from the X-ray structure $(1.87 \AA$ resolution) of the photosynthetic RC from $R b$. Sphaeroides (PDB id 2J8C). $\stackrel{24}{ }$ To reduce computational effort and yet to keep the essential feature of the isomerization mechanism, we adopted truncated models shown in Figure 3. Singlet- and triplet-state structures of 15,15'-cis and trans conformers of full SPO molecule, hereafter called as full SPO (Figure 2), and of their truncated models, hereafter simply called as SPO for the convenience, (Figure 3), were optimized followed by frequency calculations by using the B3LYP functional ${ }^{54}$, $\underline{55}$ with 6-311G $(d)$ basis set. $\frac{56}{}$ These frequency calculations were used to show that the optimized structures are minima on their respective potential energy surfaces. In the present study, we performed the calculations in gas phase. As a part of the calculations, electrostatic effect of the solvent was taken into account by a self-consistent reaction field (SCRF) with a polarized continuum model (PCM). $\frac{57}{}$ Calculations were performed with the Gaussian 09 suite of programs $\underline{58, \underline{59}}$ unless or otherwise noted. 


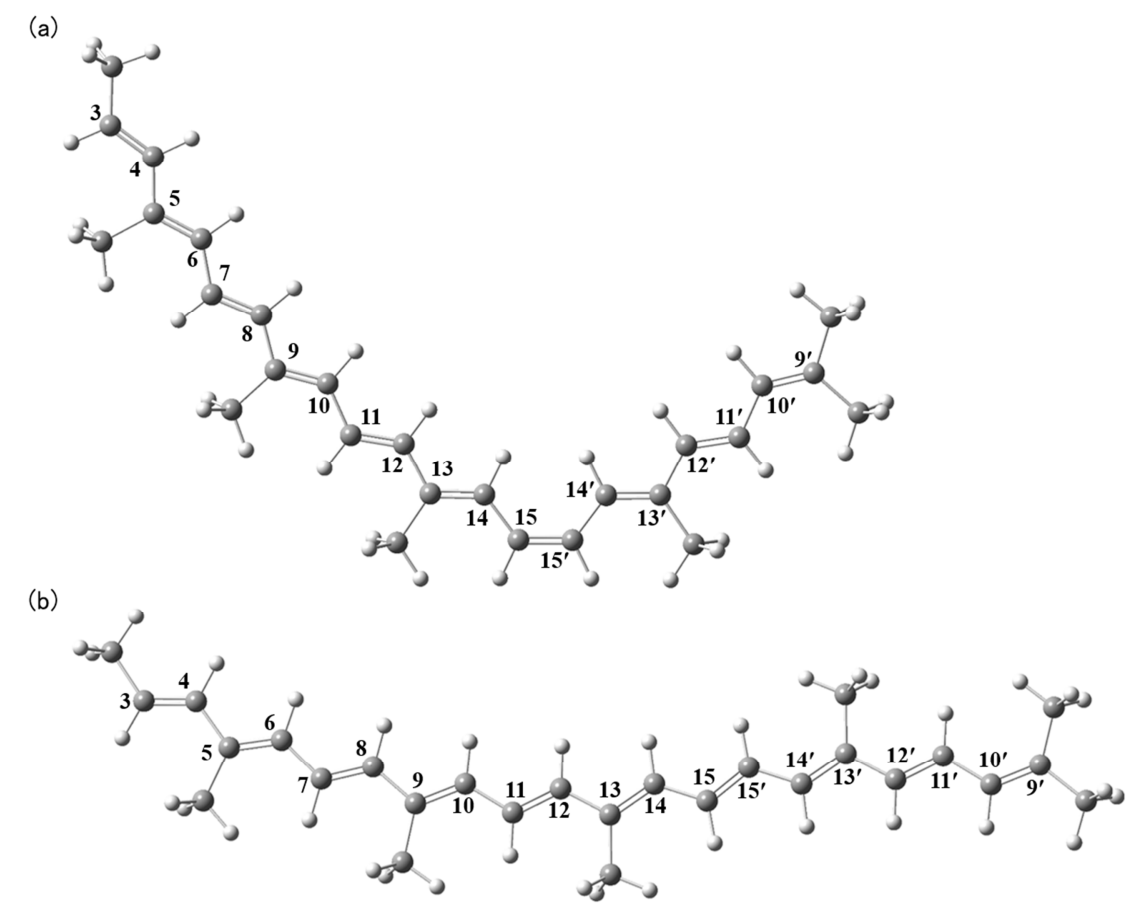

Figure 3. Structure (optimized) of the truncated (a) 15,15'-cis-SPO (b) trans-SPO.

Before going for the target system, we checked the applicability of the DFT methods for this problem by studying the rotational potential energy behaviour of a miniaturized model system of the SPO molecule (octa-2,4,6-triene, see Figure S4 in SI), a mini-model mimicking the core part of SPO molecule containing the central $\mathrm{C}=\mathrm{C}$ bond along with two other $\mathrm{C}=\mathrm{C}$ double bonds and two $\mathrm{C}-\mathrm{C}$ single bonds. The performance of various density functionals, B3LYP, BLYP, $, \underline{55}, \underline{60}$ BP86, $, \underline{60}, \underline{61}$ B3LYP*,,$\underline{20}$ M06-2X,,$\underline{63}$ M11, $\frac{64}{2}$ and B2PLYPD $\left(\right.$ ref $^{65}$ ), were checked against the second-order Moller-Plesset (MP2) level of theory, ${ }^{66,}, 67$ the coupled-cluster singles and doubles with truncated triples $[\operatorname{CCSD}(\mathrm{T})], \frac{68-70}{}$ and Brueckner doubles with truncated triples $[\mathrm{BD}(\mathrm{T})], \operatorname{ref}^{\frac{71-73}{3}}$, theories. For all the DFT calculations, 6$311 \mathrm{G}(d)$ basis set was used and for the ab initio calculations, Dunning's correlationconsistent double-zeta cc-pVDZ basis set was utilized..$^{74}$ The results (See Figure S5 in SI) showed that both the pure functionals (BP86 and BLYP) produce results that are very close to the $\operatorname{CCSD}(\mathrm{T})$ result: singlet-triplet crossing occurs at around $\phi_{\mathrm{S}-\mathrm{T}}=75^{\circ}$. In fact, the singlet energy rotational barriers obtained using these two pure functionals have the least difference with those obtained using the $\operatorname{CCSD}(\mathrm{T})$ and $\mathrm{BD}(\mathrm{T})$ theories. One other point worth to be noted here is that the calculated energy difference between the cis- and trans- forms was reproduced very well by BP86 functional. So the BP86 density functional that produced the most reliable results for the singlet-triplet crossing of the mini-model SPO was used for the triplet potential energy surface studies of all the selected SPO systems. For this, the 6- 
$311 \mathrm{G}(d)$ basis set was used. Studies clearly showed that the singlet-triplet crossing occurs along the rotation of the central C-C bonds.

To furthering the singlet-triplet crossing point closer, the minimum-energy intersystem crossing (MEISC) point was explored by using a method developed by Martinez and co-workers, ${ }^{75}$ which is originally designed for obtaining minimum energy conical intersection (MECI) without deriving energy gradient and derivative couple vectors. For the present study, an in-house program package developed by Nakayama et al. ${ }^{76}$ was used. The parameter $\alpha$ is set to be 0.02 Hartree and the threshold $\delta$ value corresponding to the maximum acceptable energy gap between the singlet and the triplet states is set to be at 0.001 Hartree. By keeping these parameters fixed, the optimizations were made with the initial $\sigma=3.5$ value. In the process, when the resulting energy gap between the singlet and triplet becomes constant and no further decrease in gap is found, we increased $\sigma$ value and repeat the optimization from the final structure of the last step. The $\sigma$ value is increased repeatedly until the gap $\Delta E_{(\mathrm{S}-\mathrm{T})} \leq \delta$. For the MEISC point exploration, the optimized singlet-triplet crossing point structure (geometry at $\phi_{\mathrm{S}-\mathrm{T}}=77^{\circ}$ ) is taken as the initial structure. Convergence behaviours and the singlet-triplet energy gap during the MEISC optimization are depicted in Figs. S7-S9. These figures show an agreeable convergence along the entire optimization steps. At the end, the final expected convergence with respect to the initial conditions occurred with $\sigma=20$. Again, calculations were performed at the BP86/6-311G $(d)$ level of theory.

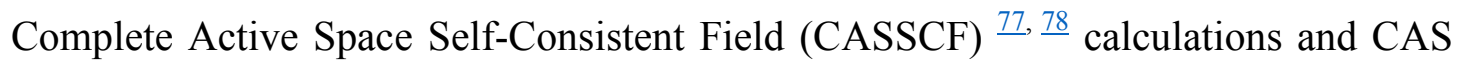
State Interaction (CASSI) calculations were performed to corroborate the DFT results for the potential energy surfaces along the central C-C bond twisting. ANO-RCC basis $\operatorname{set}^{\frac{79}{}}$ was utilized for this purpose. Spin-orbit coupling (SOC) between the singlet and triplet states was also calculated using the atomic-mean field approximation. $\stackrel{80}{21}$. MOLCAS suite of $\operatorname{programs}^{82, \underline{83}}$ was employed for the SOC calculations.

\section{Results and discussion}

\subsection{Structure and Energetics}

Ground-state (singlet) and excited triplet-state structures of both 15,15'-cis- and transSPO were optimized followed by frequency calculations at B3LYP/6-311G $(d)$ level of theory 
and the optimized ground-state structures are given in Figure 3. Both the isomers keep planarity (planar conjugated chain) in their respective ground states. In the X-ray structure of the RC purple bacteria ${ }^{24}$, the SPO structure (central conjugated part) is very close to planar$\phi\left(14,15,15^{\prime}, 14^{\prime}\right)$ is only around $3^{\circ}$. Similar to their ground state structures, the optimized triplet states of both 15,15'-cis- and trans-SPO conformers have planar structures. Repeated optimizations starting from twisted, around the central C15-C15' bond, non-planar 15,15'-cisspheroidene structure are resulted in similar planar structures (with merely $\phi=0.4^{\circ}$ ).

Earlier transient resonance-Raman spectroscopy showed that a cis configuration is retained in the triplet state,,$\frac{84}{}$ although enormous enhancement of some Raman lines strongly suggested the twisting (The weak $958 \mathrm{~cm}^{-1}$ Raman line in solution downshifted slightly and strongly enhanced upon binding to the RC and formed medium $954 \mathrm{~cm}^{-1}$ Raman line. The intensity enhancement was regarded as an indication of twisting around the $\mathrm{C} 15=\mathrm{C} 15^{\prime}$ bond).$^{31}$ Later, empirical and normal-coordinate analysis of the triplet Raman spectra of $15,15^{\prime}$-cis-SPO incorporated into the RC from $R b$. sphaeroides R26 showed twisting around the $\mathrm{C} 15=\mathrm{C} 15^{\prime}, \mathrm{C} 13=\mathrm{C} 14$, and $\mathrm{C} 11=\mathrm{C} 12$ bonds. ${ }^{34}$ So these results combined with the present gas-phase calculations show that the RC environment has a significant influence on the structure of the carotenoids.

Important structural changes noticed over triplet excitation are the changes in the conjugated $\mathrm{C}-\mathrm{C}$ bond-length alternations (BLA) - single bonds become double-bond-like and double bonds become single-bond-like. As shown in Figure 4a, such changes in carboncarbon bond lengths are noticed almost from $\mathrm{C} 6$ to $\mathrm{C} 12^{\prime}$ region. Yet, these changes are very significant between $\mathrm{C} 9$ and $\mathrm{C} 15^{\prime}$ region. To see a clear trend in change in carbon-carbon bond strength due to the triplet excitation, we calculated the bond orders of these conjugated C-C

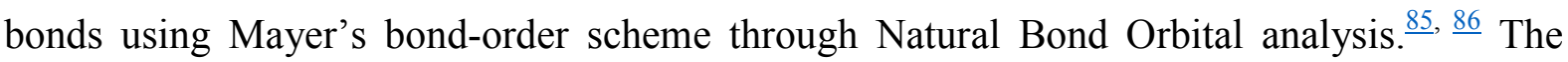
calculated values reveal that the change in bond orders, increase for the $\mathrm{C}-\mathrm{C}$ single bonds and decrease for the $\mathrm{C}=\mathrm{C}$ double bonds upon triplet excitation, is significant in the central part of the conjugated chain, i.e., between $\mathrm{C} 9$ to $\mathrm{C} 15^{\prime}$ atom region (Figure $4 \mathrm{~b}$ ). It should be noticed that by using carbon-carbon stretching force constants, calculated from the empirical normalcoordinate analysis, as a scale of bond order, Mukai-Kuroda et al. ${ }^{34}$ found large changes in bond orders in the central part of the conjugated chain upon triplet excitation. The bond orders calculated in the present DFT study support their earlier rough estimations and confirm their identification of the triplet-excited region (center of the conjugated chain), 
where the largest changes in bond orders take place, though some of their results are not noticed in the present study. For example in the $S_{0}$ state, the lowest bond order found for the $\mathrm{C} 15=\mathrm{C} 15^{\prime}$ bond, among all the $\mathrm{C}=\mathrm{C}$ bonds, and the highest $\mathrm{C}-\mathrm{C}$ bond orders exhibited around the $\mathrm{C} 14-\mathrm{C} 15$ and $\mathrm{C} 14^{\prime}-\mathrm{C} 15^{\prime}$ bonds in their study are not seen in the present study. Similarly, the highest bond order obtained for the $\mathrm{C} 12-\mathrm{C} 13$ bond, among all the $\mathrm{C}-\mathrm{C}$ bonds, in the $T_{1}$ state is not supported by the results of the present study.

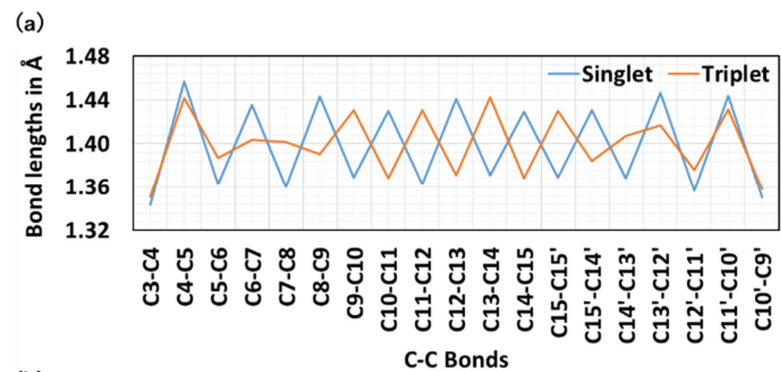

Figure 4. Conjugated (a) bond lengths and (b) bond orders in ground and excited triplet states obtained at B3LYP/6-311G(d) level.

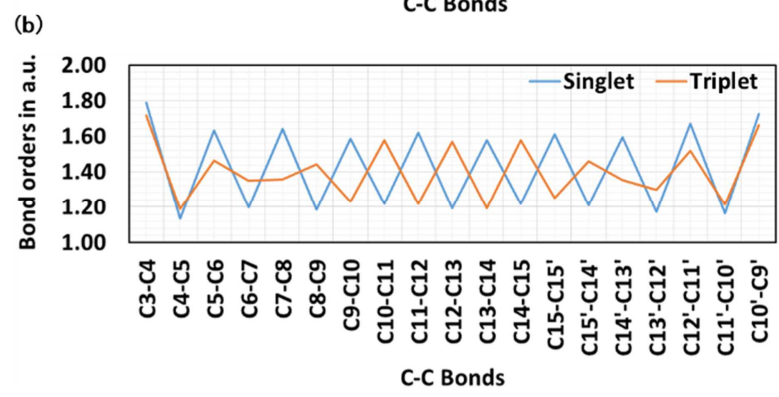

It should also be noticed that the roughly estimated ${ }^{\underline{34}}$ increase $(0.04$ to $0.05 \AA)$ in $\mathrm{C} 13=\mathrm{C} 14$ bond length due to the triplet excitation is smaller than the value $(0.071 \AA)$ obtained in the present study. Also, previously estimated lengthening of the other two $\mathrm{C}=\mathrm{C}$ bonds, $0.04 \AA$ for the $\mathrm{C} 11=\mathrm{C} 12$ bond and $0.02 \AA$ for the $\mathrm{C} 15=\mathrm{C} 15^{\prime}$ bond, are smaller than those calculated (0.067 and $0.061 \AA$, respectively) in the present study. All these calculated values clearly indicate that the change in $\mathrm{C}-\mathrm{C}$ bonds takes place ( $\mathrm{C} 5$ to $\mathrm{C} 11^{\prime}$ region) upon triplet excitation, and this change is significant in the region between $\mathrm{C} 9$ to $\mathrm{C} 15^{\prime}$.

In ground state, trans-conformer is energetically $2.51 \mathrm{kcal} / \mathrm{mol}$ more stable than the 15,15'-cis-SPO conformer at B3LYP/6-311G(d) level of theory. Almost a similar energy difference $(2.60 \mathrm{kcal} / \mathrm{mol})$ is obtained at the $\mathrm{BP} 86 / 6-311 \mathrm{G}(d)$ level. The triplet excitation does not make any noticeable difference: again, the trans-isomer is energetically 3.36 and $3.22 \mathrm{kcal} / \mathrm{mol}$ more stable than the $c i s$-isomer at the B3LYP/6-311G $(d)$ and BP86/6-311G $(d)$ level of theories, respectively. These calculated values reveal that though the cis stereoisomer is energetically less favourable, its energy difference with the trans is not substantial. 
Although its triplet state plays the most important character in the photosynthetic RC, and its role as an antioxidant has an immense importance, the triplet excitation energies of SPO are not reported before. The BP86 calculated adiabatic triplet excitation energy is 16.74 $\mathrm{kcal} / \mathrm{mol}(0.73 \mathrm{eV})$ and $16.12 \mathrm{kcal} / \mathrm{mol}(0.70 \mathrm{eV})$ for cis- and trans-SPO isomers, respectively. The calculated values have no noticeable difference with those of B3LYP functional (16.93 and $16.09 \mathrm{kcal} / \mathrm{mol}$ for cis and trans isomers, respectively). These values are comparable with experimental 0-0 excitation energy of $\beta$-carotene $\left(0.92 \mathrm{eV}^{\underline{87}}\right.$ and $\left.0.84 \mathrm{eV}^{\underline{88}}\right)$ and DFT/MRCI result $\left(0.76 \mathrm{eV}^{48}\right)$. Vertical triplet excitation energies are calculated to be $22.68 \mathrm{kcal} / \mathrm{mol}$ $(0.98 \mathrm{eV})$ and $21.82 \mathrm{kcal} / \mathrm{mol}(0.95 \mathrm{eV})$ for cis and trans isomers, respectively, at BP86/6$311 \mathrm{G}(d)$ level of theory. These values simply do not show any structural preference for the SPO pigment to extract the triplet energy of $\mathrm{BChl}$.

\subsection{Potential energy curves along the $\mathrm{C}^{2}{ }^{\prime}=\mathrm{C}^{\prime} 5^{\prime}$ bond rotation}

In this section, the results of the DFT calculations for the potential energy along the rotation around the central $\mathrm{C}=\mathrm{C}$ bond are presented, and the crossing between the singlet and triplet states is discussed to understand the triplet energy dissipation mechanism. Potential energies obtained for the SPO molecule along its central $\mathrm{C} 15=\mathrm{C} 15^{\prime}$ bond rotation is given in Figure 5. The triplet potential energy curve is obtained by optimizing its structures at fixed torsional angles, $\phi\left(\mathrm{C} 14,15,15^{\prime}, 14^{\prime}\right)$. The singlet-state potential energy curve is derived by single-point calculations at the optimized triplet structures.

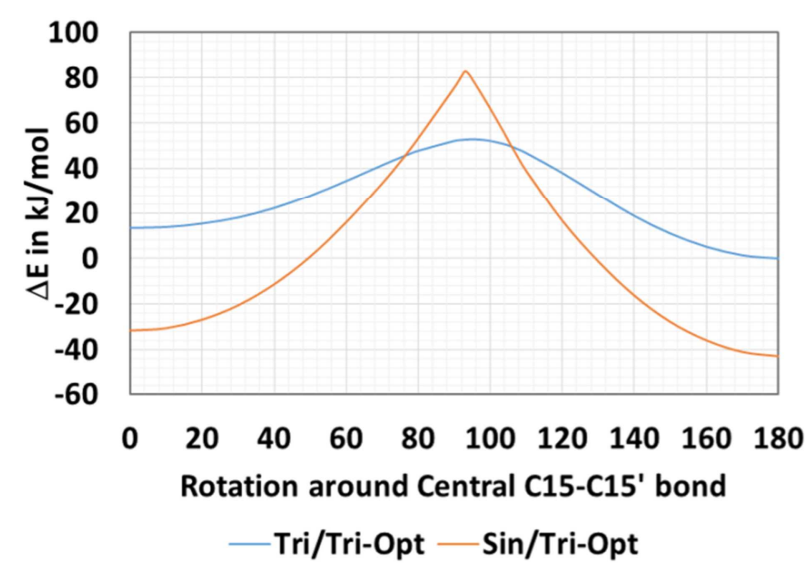

Figure 5. Potential curves for singlet and triplet states of the 15,15'-cis-SPO. Tri/Tri-Opt and $\mathrm{Sin} /$ Tri-Opt represents the triplet and singlet energies obtained at the triplet-state optimized structure.

As the figure indicates, the all-important singlet-triplet crossing occurs within the cis region (i.e., before reaching $\phi=90^{\circ}$ ) of the rotation - exactly, the calculated energies reveal that the crossing occurs at $\phi=77^{\circ}$. Figure 5 also shows that the triplet energy is considerably 
flat all along the rotation from cis- to trans- conformation, and it has a barrier of $39.4 \mathrm{~kJ} / \mathrm{mol}$ $(9.41 \mathrm{kcal} / \mathrm{mol})$ at around $\phi=95^{\circ}$. The singlet-triplet crossing point $\left(\phi_{\mathrm{S}-\mathrm{T}}=77^{\circ}\right)$ is energetically $32.5 \mathrm{~kJ} / \mathrm{mol}(7.77 \mathrm{kcal} / \mathrm{mol})$ higher than the 15,15'-cis minimum structure. The other structural parameters of the singlet-triplet crossing point that differ noticeably from the triplet $15,15^{\prime}$-cis global minima are given in Table 1 (Complete geometry at $\phi_{\mathrm{S}-\mathrm{T}}$ is given in ESI). For comparison, the corresponding parameters of singlet and triplet 15,15'-cis global minimum structures are also given in the table. Significant changes in the structure are noticed close to the central $\mathrm{C} 15-\mathrm{C} 15^{\prime}$ bond: for example, the $\mathrm{C} 15-\mathrm{C} 15^{\prime}$ bond becomes more single-bond-like, lengthened by $0.04 \AA$, and the nearby C14-15 bond turns into more doublebond-like, shortened by $0.02 \AA$. Table also reveals that the amount of lengthening/shortening of the next neighbouring single/double bonds is reduced while moving further away from the central $\mathrm{C} 15-\mathrm{C} 15^{\prime}$ bond. The maximum change in bond angle is found for C15'-C15-C14 (by $2.9^{\circ}$ ) and $\mathrm{C} 15-\mathrm{C} 15^{\prime}-\mathrm{C} 14^{\prime}$ (by $2.2^{\circ}$ ) bond angles. Also, two neighbouring dihedrals, C13-C14C15-C15' and C15-C15'-C14'-C13', have noticeable changes (by around $4^{\circ}$ ) from those of the triplet 15-15'-cis minimum energy structure. Again, as in the case with the bond lengths, smaller to negligible changes in the other angles are observed while moving away from the central C-C bond. All these results indicate that the changes in the geometrical parameters are mostly localized to the vicinity of central $\mathrm{C} 15-\mathrm{C} 15^{\prime}$ bond and the changes in some of these structural parameters, like the central $\mathrm{C}-\mathrm{C}$ bond length, played an important role in bringing down the singlet-triplet crossing.

Table 1. Important structural parameters of singlet-triplet crossing and MEISC points that vary from the minimum energy $15-15^{\prime}$-cis structure. Bond lengths are in $\AA$ and angles are in degrees

\begin{tabular}{ccccc}
\hline Parameter & $\begin{array}{c}\text { Singlet } \\
15,15^{\prime} \text {-cis- } \\
\text { stereoisomer }\end{array}$ & $\begin{array}{c}\text { Triplet } \\
15,15^{\prime} \text {-cis- } \\
\text { stereoisomer }\end{array}$ & $\begin{array}{c}\text { Singlet-triplet } \\
\text { crossing point } \\
\left(\phi_{\text {S-T }}=77^{\circ}\right)\end{array}$ & $\begin{array}{c}\text { MEISC } \\
\text { point } \\
\left(\phi=58.4^{\circ}\right)\end{array}$ \\
\hline Bond lengths: & & & & \\
$R\left(15,15^{\prime}\right)$ & 1.388 & 1.429 & 1.469 & 1.476 \\
$R(14,15)$ & 1.423 & 1.384 & 1.365 & 1.357 \\
$R(13,14)$ & 1.390 & 1.436 & 1.447 & 1.463 \\
$R(12,13)$ & 1.435 & 1.391 & 1.388 & 1.376 \\
$R\left(15^{\prime}, 14^{\prime}\right)$ & 1.425 & 1.394 & 1.372 & 1.363 \\
$R\left(14^{\prime}, 13^{\prime}\right)$ & 1.386 & 1.414 & 1.437 & 1.450 \\
$R\left(13^{\prime}, 12^{\prime}\right)$ & 1.442 & 1.421 & 1.406 & 1.398 \\
$R\left(12^{\prime}, 11^{\prime}\right)$ & 1.372 & 1.388 & 1.399 & 1.407
\end{tabular}




$\begin{array}{rrrrr}\text { Bond angles: } & & & & \\ \theta\left(15^{\prime}, 15,14\right) & 127.0 & 127.5 & 124.6 & 125.0 \\ \theta(15,14,13) & 127.6 & 126.2 & 126.6 & 126.1 \\ \theta(14,13,12) & 118.4 & 118.4 & 118.3 & 118.7 \\ \theta\left(15,15^{\prime}, 14^{\prime}\right) & 127.0 & 126.8 & 124.6 & 124.8 \\ \theta\left(15^{\prime}, 14^{\prime}, 13^{\prime}\right) & 127.7 & 128.0 & 126.6 & 126.3 \\ \theta\left(14^{\prime}, 13^{\prime}, 12^{\prime}\right) & 118.4 & 118.3 & 118.4 & 118.6\end{array}$

Dihedral angles:

\begin{tabular}{ccccc}
$\phi\left(13,14,15,15^{\prime}\right)$ & 180.0 & 179.7 & 175.9 & 179.7 \\
$\phi(12,13,14,15)$ & 179.9 & 179.9 & 178.9 & 179.2 \\
$\phi(11,12,13,14)$ & 179.9 & 179.6 & 179.7 & 178.2 \\
$\phi\left(15,15^{\prime}, 14^{\prime}, 13^{\prime}\right)$ & 179.9 & 180.0 & 175.4 & 179.7 \\
$\phi\left(15^{\prime}, 14^{\prime}, 13^{\prime}, 12^{\prime}\right)$ & 179.9 & 180.0 & 178.8 & 177.9 \\
$\phi\left(14^{\prime}, 13^{\prime}, 12^{\prime}, 11^{\prime}\right)$ & 180.0 & 180.0 & 179.3 & 177.1 \\
\hline
\end{tabular}

To further pin down the singlet-triplet crossing point, the MEISC point was explored. The converged final MEISC point structure is depicted in Figure 6. Comparing the converged geometry with the singlet-triplet crossing point $\left(\phi_{\mathrm{S}-\mathrm{T}}=77^{\circ}\right)$ structure indicates the following significant facts: the all-important central $\mathrm{C} 15=\mathrm{C} 15^{\prime}$ bond twisting is reduced to $58.4^{\circ}$. This is interesting because some reaction coordinates, in addition to the $\mathrm{C} 15-\mathrm{C} 15^{\prime}$ bond rotation, are effectively connecting between the $T_{1}$ minimum and the MEISC point. In Table 1, the structural parameters for the MEISC point are given along with those for singlet, triplet, and singlet-triplet crossing point structures. The bond-length alternation becomes stronger; the single-bond-like C-C bonds are further stretched (by maximum $0.016 \AA$ ) and the doublebond-like C-C bonds strengthened slightly (bond lengths reduced by maximum $0.012 \AA$ ). In Figure 7, we extracted the $\mathrm{C}-\mathrm{C}$ bond lengths of the conjugated chain to illustrate the structural changes. It is clear from the figure that the change in BLA towards the MEISC point is in the opposite direction from those towards the singlet minimum structure. The result indicates that this molecule can change the BLA to reach the MEISC point instead of furthering the $\mathrm{C} 15-\mathrm{C} 15^{\prime}$ bond twisting. No major twisting is seen even around the neighbouring $\mathrm{C} 13-\mathrm{C} 14$ \& $\mathrm{C} 13-\mathrm{C} 14^{\prime}$ single bonds - only a maximum of around $2^{\circ}$ twisting is noticed $\left[\phi(12,13,14,15)=179.2^{\circ}\right.$ and $\left.\phi\left(15^{\prime}, 14^{\prime}, 13^{\prime}, 12^{\prime}\right)=177.9^{\circ}\right]$. Small in-plane bending of about $5^{\circ}$ observed (Table 1) at $\mathrm{C} 14-\mathrm{C} 15 \& \mathrm{C} 15^{\prime}-\mathrm{C} 14^{\prime}$ bonds in the optimized singlet-triplet 
crossing point structure, i.e. at $\phi_{\mathrm{S} \text {-T }}=77^{\circ}$ structure, is in fact reduced and the structure becomes more planar-like in these regions $\left[\phi\left(13,14,15,15^{\prime}\right)=179.9^{\circ} \quad \&\right.$ $\left.\phi\left(15,15^{\prime}, 14^{\prime}, 13^{\prime}\right)=179 \cdot 7^{\circ}\right]$. Also the changes in the bond angles and the other dihedral angles are very minor. Conversely, slight non-planarity up to around $3^{\circ}$ are observed in some other parts of the conjugated chain, especially in the longer side of the chain. These examinations indicate that the changes in the BLA, single bonds become more single bonds and double bonds become more double bonds, though each of them is small, have played as other important reaction coordinates while reaching the MEISC point. Overall, these moderate structural changes assist the molecule in triplet state to reach the singlet-triplet ISC within $60^{\circ}$ rotation of the central $\mathrm{C} 15-\mathrm{C} 15^{\prime}$ bond. Optimization with fixed $\phi=58.4^{\circ}$ indicates that the triplet state has to move just $6.7 \mathrm{~kJ} / \mathrm{mol}(1.6 \mathrm{kcal} / \mathrm{mol})$ higher to reach the MEISC point. The calculated energy difference between the 15,15'-cis global minimum and the MEISC (at the final converged point) structures is $26.5 \mathrm{~kJ} / \mathrm{mol}(6.32 \mathrm{kcal} / \mathrm{mol})$. All these calculated values conclude that a rotation of about $55-60^{\circ}$ around the $\mathrm{C} 15-\mathrm{C} 15^{\prime}$ bond is enough to reach the transition state of this singlet-triplet crossing photochemical reaction, i.e. MEISC point. The bond length stretching at the central $\mathrm{C} 15-\mathrm{C} 15^{\prime}$ bond can assist singlet-triplet crossing efficiently.

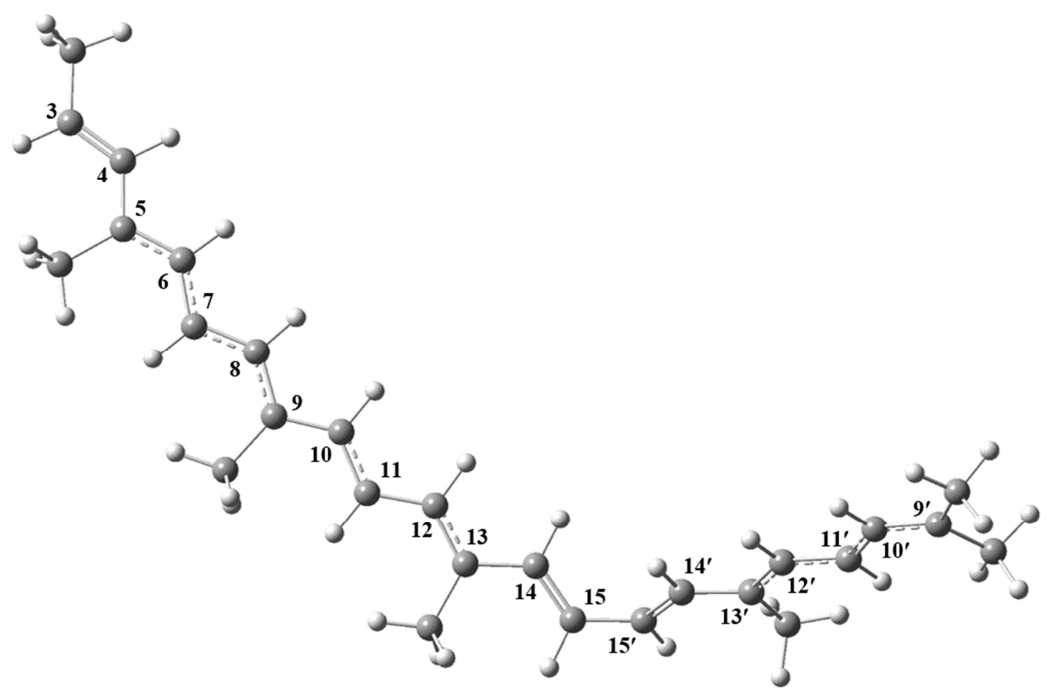

Figure 6. MEISC structure at BP86/6-311G(d). 

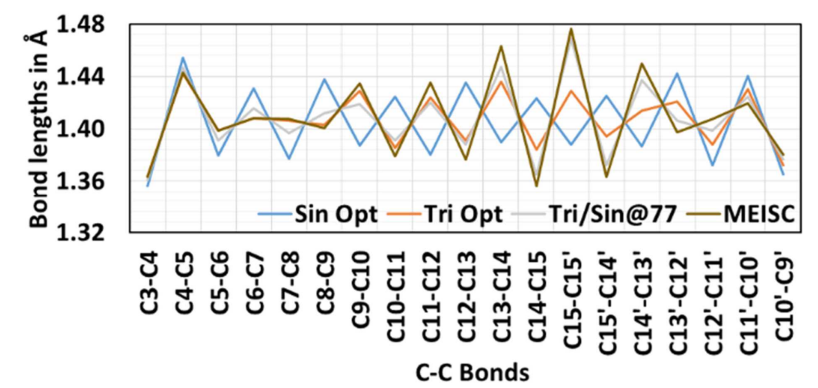

Figure 7. Conjugated $\mathrm{C}-\mathrm{C}$ bond lengths in singlet, triplet, Singlet-triplet crossing $\left(\phi_{\mathrm{S}-\mathrm{T}}=77^{\circ}\right)$, and MEISC $\left(\phi=58.4^{\circ}\right) \mathrm{BP} 86 / 6-311 \mathrm{G}(d)$ optimized structures.

Previously, the relative energy levels of the singlet excited states of carotenoid were studied, and the results showed that these are sensitive to the reaction coordinates such as $\mathrm{C}$ -

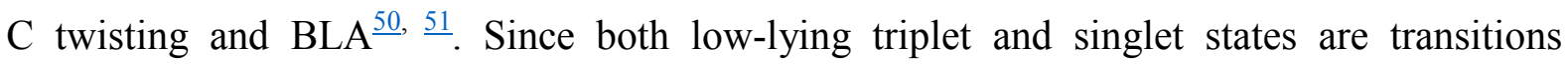
involving HOMO and LUMO, the nodal structure of these orbitals should have a common origin. As clearly seen in Figure $8(\mathrm{a}, \mathrm{b}), \mathrm{C}-\mathrm{C}$ bonds with $\pi$-bonding character in HOMO change to $\pi$-antibonding character in LUMO. In the opposite way, C-C bonds with $\pi$ antibonding character in HOMO change to $\pi$-bonding character in LUMO. This is the origin of the BLA and the bond-length change between singlet and triplet states. Moving to the MEISC point structure, the bond-lengths change to an opposite direction to the optimal bond lengths for the singlet state. Since the singlet ground state has a (HOMO) $)^{2}$ configuration, the energy of this state is expected to be unstable. On the other hand, the lowest triplet state has $(\mathrm{HOMO})^{1}(\mathrm{LUMO})^{1}$ configuration, and, therefore, the energy is expected to be insensitive to the elongating of the $\mathrm{C} 15-\mathrm{C} 15^{\prime}$ bond. To check how the change in the bond-lengths affect the potential energy, the bond-lengths of the conjugated $\mathrm{C}-\mathrm{C}$ bonds of the MEISC structure were applied to the triplet optimized structure with fixed $\phi=58.4^{\circ}$. As seen in the "Calc2" result in Figure $8 \mathrm{c}$, the changes in the bond-length of the conjugated C-C bonds decrease the singlettriplet gap from $4.4 \mathrm{kcal} / \mathrm{mol}$ to $2.1 \mathrm{kcal} / \mathrm{mol}$. The result shows that the bond-length are important reaction coordinates for the triplet-singlet crossing. We also applied the change only to the $\mathrm{C} 15-\mathrm{C} 15$ ' bond ("Calc1"). This time, the gap is reduced by $0.4 \mathrm{kcal} / \mathrm{mol}$, which indicates that it is not just the bond twisting but also the collective bond-length stretching drives to the MEISC point structure. 

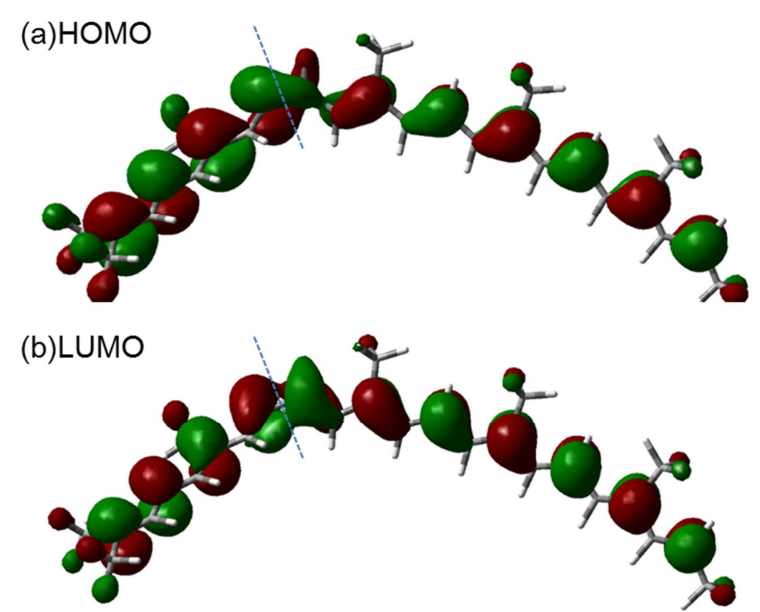

(c) Potential energy due to the structural changes

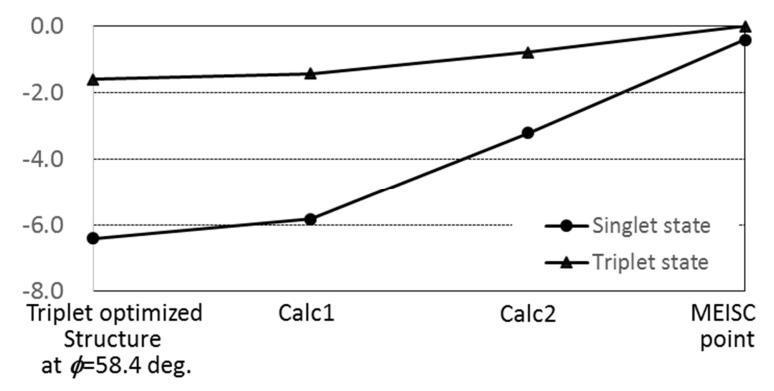

Figure 8 (a) HOMO and (b) LUMO distributions at the MEISC point structure. The twisted C15-C15' bond was shown by dotted lines. (c) Effect of bond lengths on potential energy of the singlet and triplet states. "Calc1" denotes that only the $\mathrm{C} 15-\mathrm{C} 15$ ' length was changed to that of the MEISC structure while "Calc2" denotes all the conjugated C-C bond lengths were changed.

Most of the solution experimental studies on carotenoids were performed in $n$-hexane. So we studied singlet-triplet crossing in solution by using SCRF with PCM with $n$-hexane as a solvent to understand the bulk solvent effects. The same BP86 functional with 6-311G $(d)$ basis set was used for this purpose. The calculations indicate that the planarity of the triplet $15,15^{\prime}$-cis-SPO is kept (only a mere $0.2^{\circ}$ twist is observed) as in the gas-phase and this conformer is $3.2 \mathrm{kcal} / \mathrm{mol}$ less stable than its trans counterpart. As shown in Figure S10, the calculated result in the solution was very similar to that in the gas-phase (see Figure 5 for comparison). The calculated singlet and triplet energies along the $\mathrm{C} 15=\mathrm{C} 15^{\prime}$ bond rotation also show that the singlet-triplet crossing occurs at $\phi_{\mathrm{S}-\mathrm{T}}=77^{\circ}$ at the energy $33.0 \mathrm{~kJ} / \mathrm{mol}(7.89$ $\mathrm{kcal} / \mathrm{mol}$ ) higher than the cis (triplet) energy. The calculated triplet energy barrier to the isomerization is $39.9 \mathrm{~kJ} / \mathrm{mol}(9.54 \mathrm{kcal} / \mathrm{mol})$. These results indicate that they are not influenced significantly by the electrostatic effect from the environment represented by the 
PCM. As followed in the gas-phase calculations, the MEISC point was also obtained to further narrow down the crossing point. Again, the calculated results are not different from those of gas-phase calculations.

Theoretical studies are sometimes performed in $n$-hexane solution to mimic the protein environment; however, the approximate dielectric constant $(\varepsilon)$ for a protein environment is different (4) from the $\varepsilon$ of $n$-hexane (1.88). So we repeated the SCRF-PCM calculations with $n$-hexane as a solvent but with $\varepsilon=4$. Results obtained, however, are very similar to those derived earlier: cis conformer has a planar structure $\left(\phi=0.2^{\circ}\right)$ in its triplet state, crossing occurs at $\phi=77^{\circ}$ at the height of $33.6 \mathrm{~kJ} / \mathrm{mol}(8.02 \mathrm{kcal} / \mathrm{mol})$, and the triplet isomerization barrier is calculated to be $40.5 \mathrm{~kJ} / \mathrm{mol}(9.69 \mathrm{kcal} / \mathrm{mol})$.

As mentioned at the beginning, all these calculations were made on the truncated model (Figure 3) of SPO. To check the truncation effect, we considered the whole SPO pigment, 102 atoms, and performed the calculations on 15,15'-cis- and trans-stereoisomers to study the structure and the singlet-triplet crossing at BP86/6-311G $(d)$ level of theory. As shown in Figure S11 in ESI, it is interesting to note that considering the full SPO system does not make any big difference: (1) both singlet and triplet structures of 15,15'-cis-spheroidene are fully planar near the central C-C bond $-\phi$ is as small as $0.5^{\circ}$ and $1.1^{\circ}$, respectively, (2) cis stereoisomer is less stable than the trans by $2.55 \mathrm{kcal} / \mathrm{mol}$ and $3.14 \mathrm{kcal} / \mathrm{mol}$ in its singlet and triplet states, respectively, (3) cis-to-trans isomerization barrier is calculated to be 39.5 $\mathrm{kJ} / \mathrm{mol}(9.43 \mathrm{kcal} / \mathrm{mol})$ and the singlet-triplet crossing takes place when the central $\mathrm{C} 15-\mathrm{C} 15^{\prime}$ bond twisted to $77^{\circ}$ at which the energy of the system is $32.7 \mathrm{~kJ} / \mathrm{mol}(7.80 \mathrm{kcal} / \mathrm{mol})$ higher than that of the cis conformer on the triplet energy surface. This proves the fact further that only the central part of the carotenoid involves in the triplet excitation and in the triplet energy dissipation process and hence considering the truncated model is sufficient to study the complete SPO.

\subsection{CASSCF potential energy curve along the C15-C15' bond twisting}

To check the spin-state crossing at the distorted $\mathrm{C} 15-\mathrm{C} 15^{\prime}$ angles, single-point $\operatorname{CASSCF}(10 \mathrm{e}, 10 \mathrm{o})$ calculations were also performed utilizing ANO-RCC $(3 s 2 p 1 d)$ basis set at the BP86/6-311G $(d)$ optimized geometries. Figure 9 shows the singlet-triplet intersystem 
crossing around 80 degree, and hence these CASSCF calculations support our DFT findings that the rotation along the $\mathrm{C} 15-\mathrm{C} 15^{\prime}$ bond in $15,15^{\prime}$-cis SPO makes singlet-triplet crossing.

Earlier hypothetical mechanism of triplet energy dissipation through cis-to-trans sensitized isomerization is based on one of the main assumptions that rotational motions around the central $\mathrm{C}=\mathrm{C}$ double bonds can enhance spin-orbit coupling. $\underline{31}, \underline{33}, \underline{34}$ To check this assumption, spin-orbit couplings between the singlet and triplet states were also evaluated using the CASSCF states. The calculated values (Figure 9) show that though the SOCs are not large, central $\mathrm{C}-\mathrm{C}$ bond rotation indeed enhances the spin-orbit coupling in intermediately twisted region that could assist intersystem crossing.

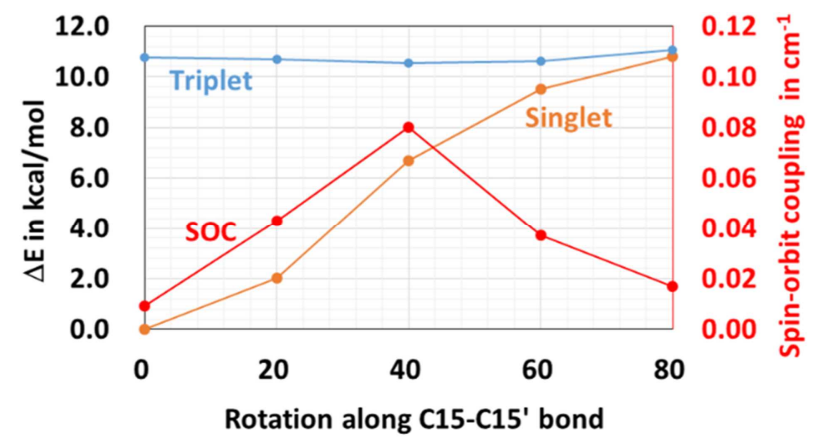

Figure 9. Spin-orbit coupling between the singlet and triplet states of 15,15'-cis-SPO. CASSCF potential energy curves of these two states along the $\mathrm{C} 15-\mathrm{C} 15^{\prime}$ bond twisting.

\subsection{Does 13,14-cis-isomer has the potential energy curves similar to 15,15 '-cis-isomer?}

Though it is well-known that SPO exists in 15,15'-cis conformer in the RCs, coexistence of 13,14-cis structure, especially in the reconstituted $R b$. sphaeroides R26, was proposed recently. ${ }^{40-42}$ In fact such a possibility, if it is proved experimentally, might have an immense biological consequence. To shed a light on this subject, we considered 13,14-cis SPO in the present investigation, and studied its structure, energetics, and possible singlettriplet crossing along the $\mathrm{C} 13-\mathrm{C} 14$ bond rotation. Again the same level of theory and calculation methodologies were used for this purpose.

Figure 10a shows the optimized 13,14-cis-SPO structure in singlet ground state. This stereoisomer is close to isoenergetic with the $15,15^{\prime}$-cis isomer - it is just $1.29 \mathrm{kcal} / \mathrm{mol}(1.44$ $\mathrm{kcal} / \mathrm{mol}$ ) lower in energy than the latter at the BP86 (B3LYP) level of calculation. In fact this new conformer has an identical singlet potential energy curve along the C13-C14 bond 
rotation with the 15,15'-cis conformer (see Figure S12). The optimized structure indicates that the central region of the conjugated carbon chain is almost planar, similar to that of the 15-15'-cis conformer. In the triplet state, cis conformers of both the isomers have identical energy [only $0.24(0.05) \mathrm{kcal} / \mathrm{mol}$ difference favouring the new cis conformer with BP86 (B3LYP) functional]. Potential energy curves showing the triplet energy dissipation due to the rotation of the $\mathrm{C} 13-\mathrm{C} 14$ bond is shown in Figure 10b. Results reveal that the singlettriplet energy crossing occurs at $\phi(12,13,14,15)=76^{\circ}$ at which point the calculated energy is $26.4 \mathrm{~kJ} / \mathrm{mol}(6.32 \mathrm{kcal} / \mathrm{mol})$ higher than the energy of the 13,14-cis conformer minimum. This energy is around $6 \mathrm{~kJ} / \mathrm{mol}(1.5 \mathrm{kcal} / \mathrm{mol})$ lower than that in the case of $15,15^{\prime}$-cis isomer. The energy barrier for the sensitized isomerization is $33.9 \mathrm{~kJ} / \mathrm{mol}(8.10 \mathrm{kcal})$, which is again around $5.4 \mathrm{~kJ} / \mathrm{mol}(1.3 \mathrm{kcal} / \mathrm{mol})$ lower than that obtained for the $15,15^{\prime}$-cis-SPO isomer.

(a)

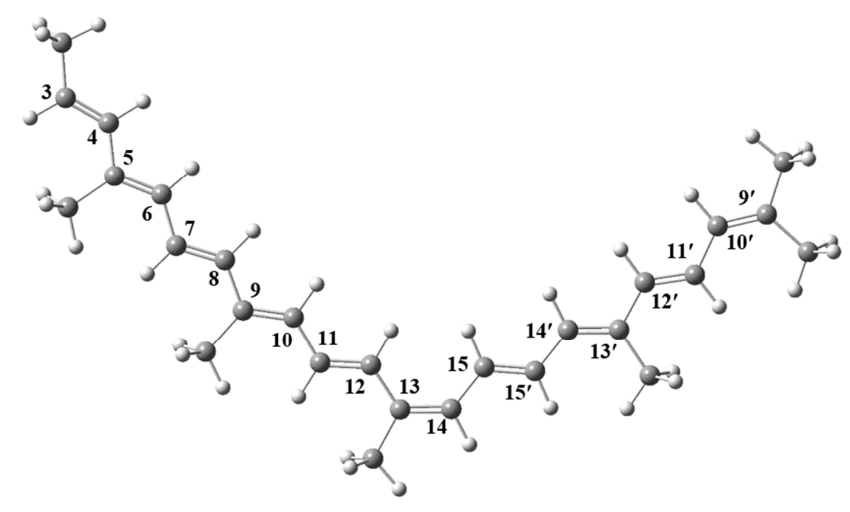

(b)

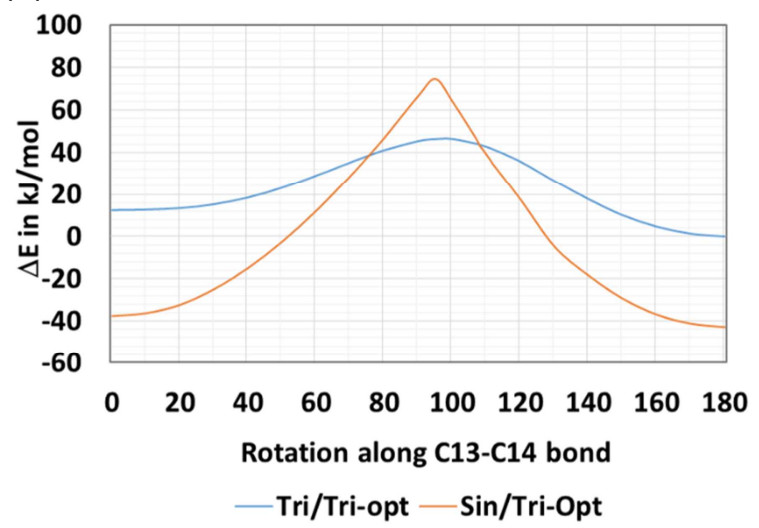

Figure 10. (a) Optimized structure of the 13,14-cis-SPO. (b) Singlet-triplet crossing of the 13,14-cis SPO. Tri/Tri-Opt and Sin/Tri-Opt represent the triplet and singlet energies obtained at the triplet optimized structures.

Thus, interestingly, none of these results disfavour the existence of the 13,14-cisspheroidene and, energetically it has similar behaviours with the $15,15^{\prime}$-cis conformer in all aspects and hence it can be considered that the steric repulsive interaction with the surrounding peptides in the RC environment might be the reason for its absence in the wildtype $\mathrm{RC}$ of $R b$. Sphaeroides. So one cannot rule out the role of the protein binding site structure in the natural selection of geometric isomers of the carotenoids in the RC. 


\subsection{Does locked-13,14-cis-spheroidene has a crossing potential curves?}

The cis-to-trans isomerization mechanism of 15,15'-cis-spheroidene for its photoprotective nature proposed by Boucher and Gingras, ${ }^{25}$ and Koyama and co-workers $\underline{26-30}$

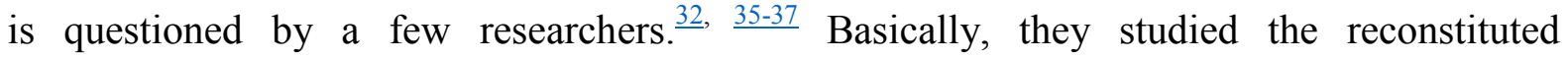
carotenoidless $R b$. sphaeroides R-26.1 in which a locked-cis-SPO, which is supposed not to isomerize to all-trans configuration, was incorporated and showed that no difference in either spectroscopic properties or the photochemistry compared to the wild-type $R b$. sphaeroides. Their conclusion is that the locked-cis-carotenoid is as capable of quenching as unlocked spheroidene, which means that cis-to-trans isomerization is not required to assist triplet energy transfer. Solving this existing controversy on this important subject is a prerequisite to understand the photoprotective mechanism of this carotenoid. For this reason, we studied the locked-13,14-cis-SPO (Figure 11a) in the present study for further understanding.

(a)

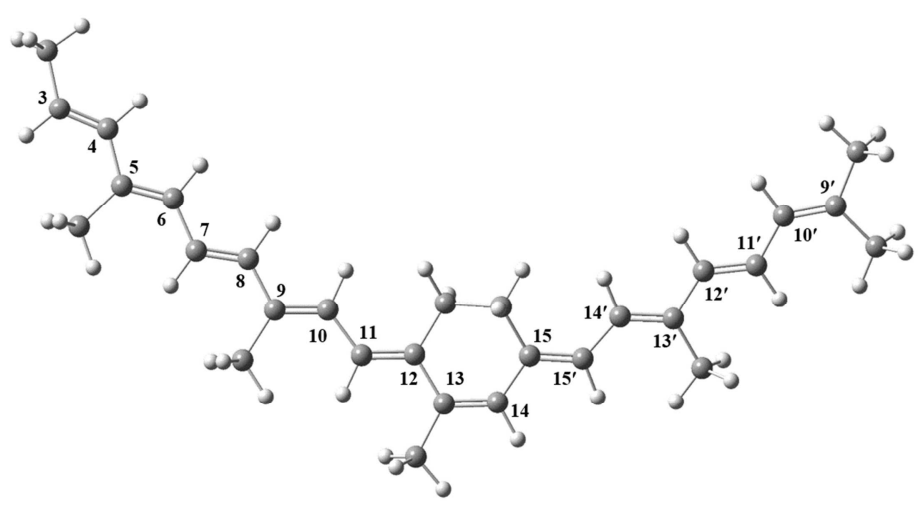

(b)

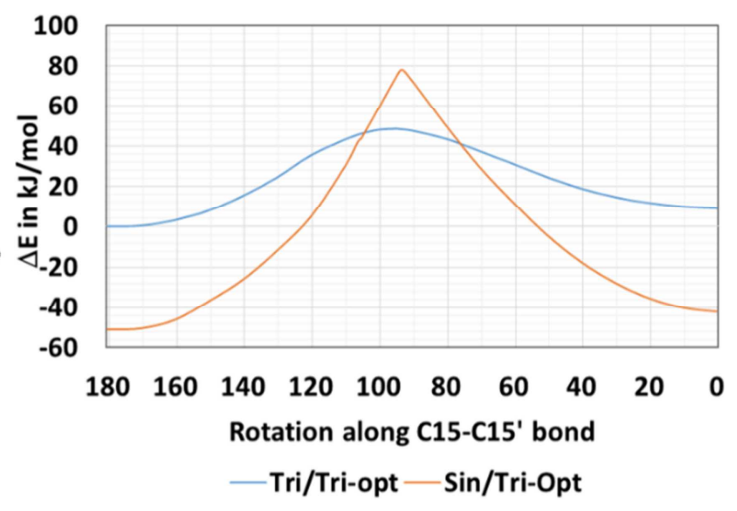

Figure 11. (a) Optimized structure of the locked-13,14-cis-SPO. (b) Singlet-triplet crossing of the locked-13,14-cis-SPO. Tri/Tri-Opt and Sin/Tri-Opt respectively represent the triplet and singlet energies obtained at optimized structures for the triplet state.

The B3LYP/6-311G $(d)$ optimized singlet structure indicates a twisting in the conjugated chain - chain in the left-side of the ring is twisted compared to that in the rightside. The neighbouring dihedrals, $\phi\left(14,15,15^{\prime}, 14^{\prime}\right)$ and $\phi(13,12,11,10)$, are calculated to be around $177^{\circ}$. Such twistings in the conjugated chain are noticed also in the triplet state. In fact, the $\phi\left(14,15,15^{\prime}, 14^{\prime}\right)$ and $\phi(13,12,11,10)$ angles in $T_{1}$ state show further rotation by up to $6^{\circ}$ from the planarity. So it is possible that the rotation around a neighbouring $\mathrm{C}-\mathrm{C}$ double bond, for example $\mathrm{C} 15-\mathrm{C} 15^{\prime}$, could provide the needed mechanism for the singlet-triplet energy 
crossing. So we studied the potential energy curves of this locked-cis system along the rotation around $\mathrm{C} 15-\mathrm{C} 15^{\prime}\left[\phi\left(14,15,15^{\prime}, 14^{\prime}\right)\right]$ bond. Results show a similar trend as that of $15,15^{\prime}$-cis, see Figure $11 \mathrm{~b}$. The triplet state crosses the singlet state at $104^{\circ}$ (rotation of $74^{\circ}$ ) at the energy height of $46.7 \mathrm{~kJ} / \mathrm{mol}(11.15 \mathrm{kcal} / \mathrm{mol})$ and the calculated barrier to the rotation is $48.6 \mathrm{~kJ} / \mathrm{mol}(11.60 \mathrm{kcal} / \mathrm{mol})$. We have also studied the energy variation in $15,15^{\prime}$-cis-full SPO along the rotation around $\mathrm{C} 14^{\prime}-\mathrm{C} 13$ ', a $\mathrm{C}-\mathrm{C}$ double bond neighbouring to the central C15-C15' bond, and the resulted potential energy curve is given in Figure S13. The figure indicates the singlet-triplet crossing at around $75^{\circ}$ with the energy of around $54.4 \mathrm{~kJ} / \mathrm{mol}(13$ $\mathrm{kcal} / \mathrm{mol}$ ). All these results clearly indicate that the twisting of the neighbouring, to the central C-C bonds, double bond can assist triplet energy dissipation. Again complete isomerization is not necessary for the crossing. Hence in the locked-cis-SPO case, though the rotation around the central double-bond is prohibited, rotation around its neighbouring C-C double bond can pave the way for a singlet-triplet energy crossing. Thus, cis-to-trans isomerization mechanism proposed for quenching is upheld! The higher singlet-triplet crossing energies obtained for the locked-13,14-cis- $(46.7 \mathrm{~kJ} / \mathrm{mol})$ and all-trans-SPO $(50.2$ $\mathrm{kJ} / \mathrm{mol}$, see Figure 5) when compared to that for 15,15'-cis-SPO $(32.5 \mathrm{~kJ} / \mathrm{mol})$ can nicely be corroborated with their slightly larger $T_{1}$ decay time constant and hence their quenching should be considered as "slow process of intersystem crossing" in a fixed conformation.

\section{Energy dissipative photo-protection mechanism}

Let us consider the possible triplet energy dissipative mechanism in detail. On the basis of the results obtained in their transient Raman and transient absorption spectroscopic studies on $\beta$-carotene and spheroidene, Koyama and co-workers $\frac{26-30}{2 u g g e s t e d ~ t h a t ~}$ cis-totrans isomerization can assist the spheroidene in functioning as a triplet trap, and they also proposed a hypothetical mechanism for the energy dissipation. Accordingly, when a slightlytwisted ground-state RC bound 15,15'-cis-spheroidene is excited to the triplet state, it isomerizes on the triplet surface and reaches to the minimum, which is substantially twisted from its ground state structure. $.^{26}, \underline{33}, \underline{34}, \underline{39}$ Then the carotenoid dissipates its triplet energy by relaxes down to the $S_{0}$ state from the triplet minimum, and then isomerizes on the $S_{0}$ surface back to the original cis structure. They speculated that the triplet potential energy minimum is shallow and so $15,15^{\prime}$-cis can isomerize all the way to the all-trans configuration after a prolonged irradiation. At the same time, their speculated triplet energy mechanism for free 
spheroidene is different: it has a very shallow triplet minimum along the rotation around the central $\mathrm{C} 15-\mathrm{C} 15^{\prime}$ bond at the cis position and a deep minimum at the all-trans position. The $S_{0}$ potential energy curve has a minimum at the $15,15^{\prime}$-cis and all-trans positions with the latter minimum has a lower energy, and the barrier at the perpendicularly twisted position. The present study supports some of these facts and explains the rest: (1) the first and the foremost is that the results strongly support the speculated mechanism - triplet energy dissipation through cis-to-trans isomerization; (2) the cis conformer has its own triplet minimum energy structure though its energy is slightly higher (around $3 \mathrm{kcal} / \mathrm{mol}$ ) than that of its trans counterpart; (3) the cis-to-trans isomerization barrier, on the triplet surface, is around $39 \mathrm{~kJ} / \mathrm{mol}(9 \mathrm{kcal} / \mathrm{mol})$ and so prolonged irradiation can make a complete cis-to-trans isomerization; (4) but, importantly, for a singlet-triplet state crossing, complete cis-to-trans isomerization is not necessary - crossing occurs within the cis region even with a lower energy barrier when the MEISC point is considered; (5) on the singlet energy surface, though the energy difference between cis and trans conformers are small (less than $3 \mathrm{kcal} / \mathrm{mol}$ ), the trans-to-cis isomerization barrier is rather large - around $117 \mathrm{~kJ} / \mathrm{mol}(28 \mathrm{kcal} / \mathrm{mol})$ - and so the reverse isomerization, back to cis form after energy dissipation from trans triplet surface, after sensitized isomerization, is ruled out on this surface and such a trans-to-cis isomerization should be considered as a remote possibility.

It is also postulated by Koyama and co-workers $\frac{26-30}{2}$ that the natural selection of the $15,15^{\prime}$-cis isomer of spheroidene in the reaction center enhances the ability of the carotenoid to dissipate its triplet energy via cis-to-trans isomerization in protein and thus natural selection plays the main role over the structure of the RC environment. They considered their following results as strong evidence for their speculation: (1) The $T_{1} \rightarrow S_{0}$ intersystem crossing takes place much faster in $15,15^{\prime}$-cis- $T_{1}(0.83 \mu \mathrm{s})$ than in all-trans- $T_{1}(4.76 \mu \mathrm{s})$; (2) The rate of cis-to-trans $T_{1}$-state isomerization for the $15,15^{\prime}$-cis is the highest; (3) The quantum yield of triplet-sensitized isomerization is maximum (0.60) for the same $15,15^{\prime}$-cis. Because of these reasons, the usage of the $15,15^{\prime}$-cis configuration, for $\mathrm{RC}$, is expected to be the most advantageous in dissipating the triplet energy. The present study beautifully supports their speculations with evidence. The calculated results, Figure 5, clearly favour the cis- over trans-conformer for dissipating the triplet state energy - the necessary rotation for reaching their respective singlet-triplet crossing points is similar for both the isomers; however, the energy required for the cis and trans isomers to reach their relevant crossing points is 32.5 and $50.2 \mathrm{~kJ} / \mathrm{mol}$, respectively. That means, trans conformer needs more energy 
of about $20 \mathrm{~kJ} / \mathrm{mol}$ than the cis. Similarly, the trans-to-cis $T_{1}$ isomerization barrier $(52.8$ $\mathrm{kJ} / \mathrm{mol}$ ) is more than cis-to-trans $T_{1}$ isomerization barrier. On the $S_{0}$ surface, trans-to-cis isomerization barrier $(117 \mathrm{~kJ} / \mathrm{mol})$ is higher than the cis-to-trans barrier $(106 \mathrm{~kJ} / \mathrm{mol})$. These values support Koyama and co-workers' claim that cis is more advantageous in quenching the excited triplet energy efficiently. ${ }^{26-30}$ Earlier studies also claimed that any cis isomer must be more favourite than the trans in dissipating the energy because quantum yield of tripletsensitized isomerization for all the selected cis isomers is much larger than the trans-to-cis isomerization quantum yield (0.04). ${ }^{33}$ The present study indicates that, as in the case of 15,15 '-cis, 13,14 -cis conformer needs only $26.4 \mathrm{~kJ} / \mathrm{mol}(6.32 \mathrm{kcal} / \mathrm{mol})$ to reach the singlettriplet crossing point, Figure $10 \mathrm{~b}$. This validates the large quantum yield of triplet-sensitized isomerization (0.52) obtained for this cis conformer, which is just next to that $(0.60)$ obtained for $15,15^{\prime}$-cis isomer. $\frac{33}{}$ So as concluded before, cis must be a favourite conformer for triplet energy dissipation.

One more point worth to be noticed here is that the quantum yield of triplet-sensitized cis-to-trans isomerization for $15,15^{\prime}$-cis- $\beta$-carotene is found ${ }^{29}$ to be 0.98 while the same for the $15,15^{\prime}$-cis-spheroidene is $0.60 . \underline{33}$ This could be related to the findings of the present study that triplet energy dissipation in the spheroidene pigment occurs within the cis region, which ultimately decreases the chance for a complete isomerization to reach all-trans. This might also explains why all-trans isomer is not easily and clearly detected in experimental studies. It can be concluded that the cis-to-trans isomerization barrier in $\beta$-carotene might be smaller than that in spheroidene or the former carotenoid needs more $\mathrm{C}-\mathrm{C}$ double bond twisting for the singlet-triplet energy crossing.

We would like to make a comment on the issue mentioned in the earlier studies that carotenoids occupy narrow binding pockets in semi-rigid environments in photosynthetic pigment-protein complexes and so they cannot undergo configurational isomerization in site because of substantial steric interferences and hence there does not appear to be any built-in advantage in either triplet energy transfer or triplet decay afforded to cis- over transcarotenoids. The present investigation clearly show that complete cis-to-trans isomerization is absolutely not necessary for the triplet energy dissipation and in fact $\mathrm{C} 15-\mathrm{C} 15^{\prime}$ bond rotation of about $55^{\circ}-60^{\circ}$ is enough for the singlet-triplet energy crossing. Examining the recent X-ray structure ${ }^{24}$ (PDB id 2J8C) reveals that the longer conjugated side of the carotenoid $15,15^{\prime}$-cis-spheroidene in $R b$. Sphaeroides is relatively free though the other side of the conjugated chain is tightly squeezed between two helix strands (See Figure S14). The 
flexible side of the spheroidene is mainly packed with the flexible tail of the M-side BChl and a few amino acid side chains. So one can think that a rotation of about $60^{\circ}$ for the carotenoid spheroidene should be possible in the semi-rigid region. Also, such a rotation in the binding pocket might become feasible when some of the amino acid side chain changes their conformation efficiently. When nature has the capacity to pick different conformers for different purposes, trans in LH antenna complexes and cis in bacterial reaction centers, it is not unlikely for it to make such a needed conformational changes of the amino acid side chains to allow the carotenoid to accomplish its task.

\section{Concluding remarks}

Density functional theory studies are made to understand the triplet energy relaxation mechanism of the carotenoid spheroidene found in bacterial photosynthetic reaction centers. The present study clearly shows that the sensitized cis-to-trans isomerization is a possible mechanism for the $15,15^{\prime}$-cis-spheroidene to efficiently dissipate its excited triplet energy, excited by quenching the bacteriochlorophyll special pair or singlet oxygen molecule, through singlet-triplet crossing. With the rotation around the $\mathrm{C} 15-\mathrm{C} 15^{\prime}$ bond as a reaction coordinate, we performed the relaxed potential energy scan calculations. State crossing occurs at $77^{\circ}$ of central $\mathrm{C} 15-\mathrm{C} 15^{\prime}$ bond twisting at the energy height of around $32.5 \mathrm{~kJ} / \mathrm{mol}$ $(7.77 \mathrm{kcal} / \mathrm{mol})$. So a complete isomerization to all-trans is not necessary for the singlettriplet crossing though the barrier to isomerization is as small as $39.4 \mathrm{~kJ} / \mathrm{mol}(9.41 \mathrm{kcal} / \mathrm{mol})$. Studying the minimum energy intersystem crossing point concludes that triplet relaxation could start happening as soon as $55^{\circ}$ of rotation at which the energy is just $26.5 \mathrm{~kJ} / \mathrm{mol}(6.32$ $\mathrm{kcal} / \mathrm{mol}$ ) higher than that of the $15,15^{\prime}$-cis minimum on the $T_{1}$ surface. Along with the central $\mathrm{C} 15-\mathrm{C} 15^{\prime}$ bond twisting, the bond stretching of the conjugated $\mathrm{C}-\mathrm{C}$ bonds contribute in easy state crossing. CASSCF potential energy curves also show that intersystem crossing occurs upon central $\mathrm{C} 15-\mathrm{C} 15^{\prime}$ bond rotation. Spin-orbit couplings along the central C-C bond twisting are calculated and the results indicate that twisting enhances spin-orbit coupling.

The energy barrier for trans-to-cis isomerization on the $T_{1}$ surface is $52.8 \mathrm{~kJ} / \mathrm{mol}$ $(12.63 \mathrm{kcal} / \mathrm{mol})$ and for a singlet-triplet crossing, trans isomer needs at least $5 \mathrm{kcal} / \mathrm{mol}$ more energy than that the cis isomer needs. Also, the trans-to-cis energy barrier on the $S_{0}$ surface is significantly large $(117 \mathrm{~kJ} / \mathrm{mol})$. All these results indicate, without ambiguity, that sensitized central $\mathrm{C}-\mathrm{C}$ bond twisting of the $\mathrm{cis}$ isomer is the mechanism for the triplet energy relaxation 
for the spheroidene pigment. Results also support the earlier speculation that cis configuration is expected to be more advantageous, than trans counterpart, in dissipating the triplet energy. So there is a venue to conclude that nature's selection of the particular conformer of the spheroidene carotenoid is based on the requirement to finish a particular biological task. Nevertheless, the studies on 13,14-cis-spheroidene provide a modest twist on this assumption: this new isomer is isoenergetic with the popular $15,15^{\prime}$-cis isomer and its potential energy surface showing the singlet-triplet state crossing is very much identical with that of the latter. So the question is why the nature selects $15,15^{\prime}$-cis over 13,14 -cis isomer. Whether the selection of this 13,14-cis isomer is influenced by the structure of the protein binding packet is remains to be seen. By any means, the present results strongly support the recent conclusions $\frac{40-42}{2}$ that spheroidene occurs in two configurations.

Rotation around the neighbouring $\mathrm{C}-\mathrm{C}$ double bond $\left(\mathrm{C} 15-\mathrm{C} 15^{\prime}\right)$ could cause the required singlet-triplet crossing for the locked-13,14-cis to dissipate its triplet energy and hence no difference in spectroscopic properties or the photochemistry was found between the wild-type $R b$. sphaeroides and the locked-cis isomer reconstituted $R b$. sphaeroides. So the present study overcomes the controversy existing on the triplet relaxation mechanism of this carotenoid spheroidene and it supports that this carotenoid dissipates its excited triplet energy through twisting its central C-C double bonds.

The present study focused on the characteristic feature of the potential energy surfaces of the singlet and triplet states of the SPO molecule itself. Our result shed light on the existing controversies in terms of the DFT potential energy surfaces. The interactions with the protein environment is, however, a remaining question to be clarified, because they would introduce other complexities ${ }^{\underline{89}}$ due to the explicit hydrogen-bondings and other charged residues in the protein environment.

\section{Electronic Supplementary Information (ESI) available:}

Optimized structures of singlet-triplet crossing and MEISC points, convergence behaviour of singlet-triplet energy gap during MEISC optimization, some additional singlettriplet crossing potential energy surfaces. 


\section{Acknowledgements}

This study was supported by JST-CREST. This study was also supported by JSPS KAKENHI (Grant Number 24350008, 15K06563 and 15K20832) and Strategic Programs for Innovative Research (SPIRE). A portion of the computations was carried out at RCCS (Okazaki, Japan) and ACCMS (Kyoto University).

Keywords: photoreaction center - carotenoid spheroidene - photo-protective mechanism • cis-to-trans isomerization $\bullet$ density functional theory $\bullet$ singlet-triplet crossing $\bullet$ minimumenergy intersystem crossing 


\section{References}

1. R. J. Cogdell and H. A. Frank, Biochimica Et Biophysica Acta, 1987, 895, 63-79.

2. H. A. Frank and R. J. Cogdell, in Carotenoids in Photosynthesis, eds. A. Young and G. Britton, Chapman \& Hall, London, 1993, pp. 252-326.

3. Y. Koyama, Journal of Photochemistry and Photobiology B-Biology, 1991, 9, $265-$ 280.

4. H. A. Frank and R. J. Cogdell, Photochemistry and Photobiology, 1996, 63, 257-264.

5. G. Britton, S. Liaaen-Jensen and H. Pfander, Carotenoids: Natural functions, Birkhauser Verlag, Basel, 2008.

6. S. Lin, E. Katilius, A. K. W. Taguchi and N. W. Woodbury, Journal of Physical Chemistry B, 2003, 107, 14103-14108.

7. S. Lin, E. Katilius, R. P. Ilagan, G. N. Gibson, H. A. Frank and N. W. Woodbury, Journal of Physical Chemistry B, 2006, 110, 15556-15563.

8. T. Ritz, A. Damjanovic, K. Schulten, J. P. Zhang and Y. Koyama, Photosynthesis Research, 2000, 66, 125-144.

9. A. Damjanovic, T. Ritz and K. Schulten, Biophysical Journal, 1998, 74, A76-A76.

10. A. Damjanovic, T. Ritz and K. Schulten, Physical Review E, 1999, 59, 3293-3311.

11. A. Damjanovic, T. Ritz and K. Schulten, Biophysical Journal, 1999, 76, A239-A239.

12. A. Telfer, S. Dhami, S. M. Bishop, D. Phillips and J. Barber, Biochemistry, 1994, 33, 14469-14474.

13. C. S. Foote, in Free radicals in Biology, ed. W. A. Pryor, Academic Press, New York, 1976, vol. II.

14. A. deWinter and S. G. Boxer, Journal of Physical Chemistry B, 1999, 103, 8786-8789.

15. H. A. Frank, in The photosynthetic reaction center, eds. J. R. Norris and J. Deisenhofer, Academic Press, New York, 1993, vol. 2, ch. 9, pp. 221-237.

16. Y. Koyama and H. Hashimoto, in Carotenoids in photosynthesis eds. A. Young and G. Britton, Chapmann \& Hall, London, 1993, pp. 327-409.

17. Y. Koyama, M. Kuki, P. O. Andersson and T. Gillbro, Photochemistry and Photobiology, 1996, 63, 243-256.

18. A. Telfer, Philosophical Transactions of the Royal Society of London Series BBiological Sciences, 2002, 357, 1431-1439. 
19. R. J. Cogdell, T. D. Howard, R. Bittl, E. Schlodder, I. Geisenheimer and W. Lubitz, Philosophical Transactions of the Royal Society of London Series B-Biological Sciences, 2000, 355, 1345-1349.

20. P. Horton, A. V. Ruban and A. J. Young, Photochemistry of Carotenoids, 1999, 8, 271-291.

21. K. K. Niyogi, O. Bjorkman and A. R. Grossman, Proceedings of the National Academy of Sciences of the United States of America, 1997, 94, 14162-14167.

22. A. V. Ruban, R. Berera, C. Ilioaia, I. H. M. van Stokkum, J. T. M. Kennis, A. A. Pascal, H. van Amerongen, B. Robert, P. Horton and R. van Grondelle, Nature, 2007, 450, 575-U522.

23. S. Santabarbara and D. Carbonera, The Journal of Physical Chemistry B, 2005, 109, 986-991.

24. J. Koepke, E.-M. Krammer, A. R. Klingen, P. Sebban, G. M. Ullmann and G. Fritzsch, Journal of Molecular Biology, 2007, 371, 396-409.

25. F. Boucher and G. Gingras, Photochemistry and Photobiology, 1984, 40, 277-281.

26. M. Kuki, M. Naruse, T. Kakuno and Y. Koyama, Photochemistry and Photobiology, 1995, 62, 502-508.

27. H. Hashimoto and Y. Koyama, Journal of Physical Chemistry, 1988, 92, 2101-2108.

28. H. Hashimoto, Y. Koyama, K. Ichimura and T. Kobayashi, Chemical Physics Letters, $1989,162,517-522$.

29. M. Kuki, Y. Koyama and H. Nagae, Journal of Physical Chemistry, 1991, 95, 71717180.

30. Y. Koyama, Y. Mukai and M. Kuki, SPIE (Laser Spectroscopy of Bio-molecules), 1993, 1921, 191-202.

31. N. Ohashi, N. KoChi, M. Kuki, T. Shimamura, R. J. Cogdell and Y. Koyama, Biospectroscopy, 1996, 2, 59-69.

32. J. A. Bautista, V. Chynwat, A. Cua, F. J. Jansen, J. Lugtenburg, D. Gosztola, M. R. Wasielewski and H. A. Frank, Photosynthesis Research, 1998, 55, 49-65.

33. R. Fujii, K. Furuichi, J. P. Zhang, H. Nagae, H. Hashimoto and Y. Koyama, Journal of Physical Chemistry A, 2002, 106, 2410-2421.

34. Y. Mukai-Kuroda, R. Fujii, N. Ko-chi, T. Sashima and Y. Koyama, Journal of Physical Chemistry A, 2002, 106, 3566-3579.

35. Z. D. Pendon, J. O. Sullivan, I. van der Hoef, J. Lugtenburg, A. Cua, D. F. Bocian, R. R. Birge and H. A. Frank, Photosynthesis Research, 2005, 86, 5-24. 
36. Z. D. Pendon, G. N. Gibson, I. van der Hoef, J. Lugtenburg and H. A. Frank, Journal of Physical Chemistry B, 2005, 109, 21172-21179.

37. Z. D. Pendon, I. der Hoef, J. Lugtenburg and H. A. Frank, Photosynthesis Research, 2006, 88, 51-61.

38. A. W. Roszak, K. McKendrick, A. T. Gardiner, I. A. Mitchell, N. W. Isaacs, R. J. Cogdell, H. Hashimoto and H. A. Frank, Structure, 2004, 12, 765-773.

39. Y. Kakitani, R. Fujii, Y. Koyama, H. Nagae, L. Walker, B. Salter and A. Angerhofer, Biochemistry, 2006, 45, 2053-2062.

40. A. C. Wirtz, M. C. van Hemert, J. Lugtenburg, H. A. Frank and E. J. J. Groenen, Biophysical Journal, 2007, 93, 981-991.

41. G. Mathies, M. C. van Hemert, P. Gast, K. B. S. S. Gupta, H. A. Frank, J. Lugtenburg and E. J. J. Groenen, Journal of Physical Chemistry A, 2011, 115, 9552-9556.

42. J. M. Boereboom, M. C. van Hemert and J. Neugebauer, Chemphyschem, 2011, 12, 3157-3169.

43. K. Schulten and M. Karplus, Chemical Physics Letters, 1972, 14, 305-\&.

44. K. Schulten, I. Ohmine and M. Karplus, Journal of Chemical Physics, 1976, 64, $4422-4441$.

45. D. Ghosh, J. Hachmann, T. Yanai and G. K. L. Chan, Journal of Chemical Physics, 2008, 128.

46. C. M. Marian, S. C. Kock, C. Hundsdorfer, H. D. Martin, W. Stahl, E. Ostroumov, M. G. Muller and A. R. Holzwarth, Photoch Photobio Sci, 2009, 8, 270-278.

47. E. Ostroumov, M. G. Muller, C. M. Marian, M. Kleinschmidt and A. R. Holzwarth, Phys Rev Lett, 2009, 103.

48. M. Kleinschmidt, C. M. Marian, M. Waletzke and S. Grimme, Journal of Chemical Physics, 2009, 130.

49. J. P. Ceron-Carrasco, A. Requena and C. M. Marian, Chemical Physics, 2010, 373, 98-103.

50. M. Macernis, J. Sulskus, C. D. P. Duffy, A. V. Ruban and L. Valkunas, Journal of Physical Chemistry A, 2012, 116, 9843-9853.

51. S. Knecht, C. M. Marian, J. Kongsted and B. Mennucci, Journal of Physical Chemistry B, 2013, 117, 13808-13815.

52. J. P. Gotze, D. Kroner, S. Banerjee, B. Karasulu and W. Thiel, Chemphyschem, 2014, $15,3391-3400$. 
53. O. Andreussi, S. Knecht, C. M. Marian, J. Kongsted and B. Mennucci, J Chem Theory Comput, 2015, 11, 655-666.

54. A. D. Becke, Journal of Chemical Physics, 1993, 98, 5648-5652.

55. C. T. Lee, W. T. Yang and R. G. Parr, Physical Review B, 1988, 37, 785-789.

56. R. Krishnan, J. S. Binkley, R. Seeger and J. A. Pople, Journal of Chemical Physics, 1980, 72, 650-654.

57. J. Tomasi, B. Mennucci and R. Cammi, Chem. Rev., 2005, 105, 2999-3093.

58. M. J. Frisch, G. W. Trucks and H. B. Schlegel, Journal, 2010.

59. M. J. Frisch, G. W. Trucks and H. B. Schlegel, Journal, 2013.

60. A. D. Becke, Physical Review A, 1988, 38, 3098-3100.

61. J. P. Perdew, Physical Review B, 1986, 33, 8822-8824.

62. Journal.

63. Y. Zhao and D. G. Truhlar, Theoretical Chemistry Accounts, 2008, 120, 215-241.

64. R. Peverati and D. G. Truhlar, Journal of Physical Chemistry Letters, 2011, 2, 28102817.

65. T. Schwabe and S. Grimme, Physical Chemistry Chemical Physics, 2007, 9, 33973406.

66. C. Moller and M. S. Plesset, Physical Review, 1934, 46, 0618-0622.

67. M. Head-Gordon, J. A. Pople and M. J. Frisch, Chemical Physics Letters, 1988, 153, 503-506.

68. G. D. Purvis and R. J. Bartlett, Journal of Chemical Physics, 1982, 76, 1910-1918.

69. G. E. Scuseria, C. L. Janssen and H. F. Schaefer, Journal of Chemical Physics, 1988, 89, $7382-7387$.

70. J. A. Pople, M. Head-Gordon and K. Raghavachari, Journal of Chemical Physics, 1987, 87, 5968-5975.

71. C. E. Dykstra, Chemical Physics Letters, 1977, 45, 466-469.

72. N. C. Handy, J. A. Pople, M. Head-Gordon, K. Raghavachari and G. W. Trucks, Chemical Physics Letters, 1989, 164, 185-192.

73. R. Kobayashi, N. C. Handy, R. D. Amos, G. W. Trucks, M. J. Frisch and J. A. Pople, Journal of Chemical Physics, 1991, 95, 6723-6733.

74. T. H. Dunning, Journal of Chemical Physics, 1989, 90, 1007-1023.

75. B. G. Levine, J. D. Coe and T. J. Martinez, Journal of Physical Chemistry B, 2008, $112,405-413$. 
76. A. Nakayama, Y. Harabuchi, S. Yamazaki and T. Taketsugu, Physical Chemistry Chemical Physics, 2013, 15, 12322-12339.

77. B. O. Roos, P. R. Taylor and P. E. M. Siegbahn, Chemical Physics, 1980, 48, 157-173.

78. B. O. Roos, in Ab initio methods in Quantum Chemistry - II, ed. K. P. Lawley, John Wiley \& Sons, New York, 1987, pp. 399-446.

79. B. O. Roos, R. Lindh, P. A. Malmqvist, V. Veryazov and P. O. Widmark, Journal of Physical Chemistry A, 2004, 108, 2851-2858.

80. B. A. Hess, C. M. Marian, U. Wahlgren and O. Gropen, Chemical Physics Letters, 1996, 251, 365-371.

81. B. Schimmelpfennig, Journal, 1996.

82. F. Aquilante, L. De Vico, N. Ferre, G. Ghigo, P.-A. Malmqvist, P. Neogrady, T. B. Pedersen, M. Pitonak, M. Reiher, B. O. Roos, L. Serrano-Andres, M. Urban, V. Veryazov and R. Lindh, Journal of Computational Chemistry, 2010, 31, 224-247.

83. G. Karlstrom, R. Lindh, P. A. Malmqvist, B. O. Roos, U. Ryde, V. Veryazov, P. O. Widmark, M. Cossi, B. Schimmelpfennig, P. Neogrady and L. Seijo, Computational Materials Science, 2003, 28, 222-239.

84. M. Lutz, L. Chinsky and P. Y. Turpin, Photochemistry and Photobiology, 1982, 36, 503-515.

85. I. Mayer, Journal of Computational Chemistry, 2007, 28, 204-221.

86. A. E. Reed, R. B. Weinstock and F. Weinhold, Journal of Chemical Physics, 1985, 83, 735-746.

87. G. Marston, T. G. Truscott and R. P. Wayne, J. Chem. Soc., Faraday Trans., 1995, 91, 4059-4061.

88. C. Lambert and R. W. Redmond, Chem. Phys. Letters, 1994, 228, 495-498.

89. M. Macernis, B. P. Kietis, J. Sulskus, S. H. Lin, M. Hayashi and L. Valkunas, Chemical Physics Letters, 2008, 466, 223-226. 


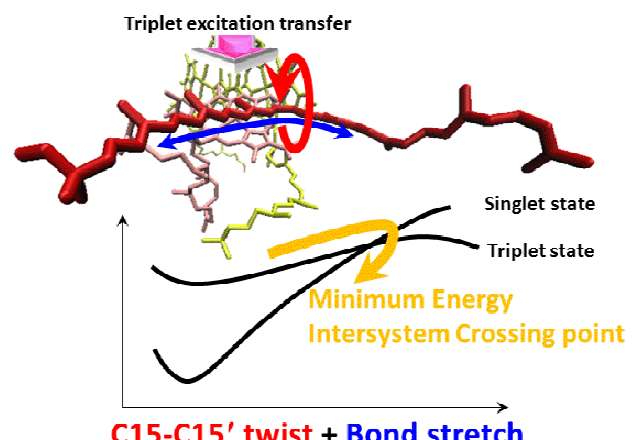

Triplet energy dissipation mechanism of a carotenoid: just bond twisting and stretching lead to minimum energy intersystem crossing point 